\title{
»daß ich zu keiner gebeimen Gesellschaft [...] weder gehöre noch je in Zukunft gebören werde" Der Illuminateneid und seine Nachfolger im bayerischen Militär vom Ende des 18. Jahrhunderts bis zum Ersten Weltkrieg
}

von

\author{
Gundula Gahlen
}

Abstract: Bayerische Offiziere waren zu einem hoben Prozentsatz im Illuminatenorden vertreten, wenngleich sie keine fübrenden Positionen innehatten. Als Reaktion auf das Wirken des Ordens in Bayern wurde 1790 der Eid gegen geheime Gesellschaften für militärische Funktionsträger verbindlich vorgeschrieben, der eine Mitgliedschaft in gebeimen Vereinigungen kategorisch ausschloss. Mit leichten Abwandlungen blieb dieser Eid bis zum Ende der bayerischen Armee 1918 in Kraft. Der Beitrag untersucht das Verbältnis zwischen dem Militär und geheimen Gesellschaften in Bayern, die hieraus resultierenden Unterwanderungsängste sowie die Bedeutung der katholischen Kirche für die Aufrechterhaltung des Verbots. Er stellt den Kontrast zwischen den harten normativen Regelungen gegen Geheimbünde und der milden Verfolgungs- und Strafpraxis heraus und erklärt ibn mit der persönlichen Beziebung zwischen dem König und seinen Offizieren sowie dem Korpsgeist im Offizierskorps.

Seltsam mutet es an, wenn bayerische Soldaten, die im Ersten Weltkrieg zu Offizieren der Linie oder der Reserve befördert wurden, entsprechend »der Allerböchsten Verordnung vom 13. Sept. 1814 'geheime Gesellschaften betreffend durch deren deutliche Verlesung in Kenntnis gesetzt « wurden und den schriftlichen Eid abgeben mussten: "Ich schwöre, daß ich zu keiner gebeimen Gesellschaft oder zu irgend einer Verbindung, deren Zweck dem Staate unbekannt, von demselben nicht gebilligt oder dem Interesse des Staates fremd ist, weder geböre noch je in Zukunft gebören werde und bin bereit, diese meine Versicherung durch einen Eid zu bekräftigen, wie ich sie jetzt schon durch meine Unterschrift bestätige. " ${ }^{1}$ Während der Fahneneid ${ }^{2}$ schon beim Eintritt

Vgl. hier z. B. Hauptstaatsarchiv München, Abt. 4 Kriegsarchiv (HStA-KA), OP 7647, darin: Protokoll über die Verpflichtung des Herrn Leutnant d. R. Rudolf Vogl vom 2.10.1915. Den Verpflichtungsakt bestätigte eine Kommission, der ein Major als Vorstand, ein Hauptmann, ein Oberleutnant und ein Regimentsauditeur angehörten.

2 Synonym werden teilweise auch die Begriffe Diensteid oder Treueid in Bayern gebraucht. Vgl. zur vielfältigen Begrifflichkeit in allen Teilen Deutschlands Sven Lange, Der Fahneneid. Die Geschichte der Schwurverpflichtung im deutschen Militär, Temmen 2002, zur Begrifflichkeit bes. S. 11-14. Siehe daneben Theodor Schieder, Der Fahneneid als politisches Problem in der deutschen Geschichte. In: Der Fahneneid. Die Stellung des Soldaten in Staats und Gesellschaft. Ein Cappenberger Gespräch, Köln 1970, S. 15-34; Peter Dade, Fahneneid und feierliches Gelöbnis. Zur militärischen Verpflichtungsform in der deutschen Wehrgeschichte, insbesondere zur geltenden Regelung für die Soldaten der Bundeswehr, Kiel 1970, S. 14 ff.; Carmen Winkel, 
in das Heer geleistet wurde, vervollständigte dieser weitere Schwur die Vereidigung des bayerischen Offiziers ${ }^{3}$.

Blickt man auf die Geschichte dieser Eidesformel, wie sie sich anhand der Akten des Kriegsministeriums und des Alten Bestandes im Bayerischen Kriegsarchiv ablesen lässt $\mathrm{t}^{4}$, wird deutlich, dass die Verordnung von $1814^{5}$ noch mehrere Vorläufer hatte. Seit 1790 war der Eid gegen geheime Gesellschaften für Offiziere und Militärbeamte ebenso wie auch für zivile und geistliche Funktionsträger ${ }^{6}$ in Bayern verbindlich vorgeschrieben, wurde allerdings damals noch Illuminateneid genannt, und war ein Teil der Maßnahmen, die gegen den Illuminatenorden getroffen wurden.

Anhand des Illuminateneids und seiner Nachfolger wird im Folgenden das Verhältnis zwischen dem Militär und geheimen Gesellschaften in Bayern vom Ende des 18. Jahrhunderts bis zum Ersten Weltkrieg nachgezeichnet. Neben der übergreifenden Frage, wer mit dem Passus geheime Gesellschaften zu welcher Zeit gemeint war, stehen drei Problemstellungen dabei im Mittelpunkt. Zum Ersten wird der Blick darauf gerichtet, inwieweit militärische Funktionsträger in geheimen Gesellschaften aktiv waren, wie geheime Gesellschaften auf das Militär Einfluss nahmen und inwiefern sie eine Bedrohung für die herrschende Ordnung darstellten. Des Weiteren werden die Argumente analysiert, warum militärischen Funktionsträgern die Mitgliedschaft in geheimen Gesellschaften verwehrt wurde. Welche Ängste verbargen sich hinter den Bestimmungen und wie wandelte sich die Argumentation vom Ende des 18. Jahrhunderts bis zum Ersten Weltkrieg? Und schließlich wird ein dritter inhaltlicher Schwerpunkt darauf gelegt, die Verfolgungs- und Bestrafungspraxis gegenüber Geheimbundangehörigen im Heer genauer zu untersuchen. Inwieweit stimmte diese mit den jeweils geltenden normativen Regelungen überein?

Eid, Uniform und Wachtdienst: Initiationsrituale im frühneuzeitlichen Offizierkorps. In: Übergänge schaffen. Ritual und Performanz in der frühneuzeitlichen Militärgesellschaft. Hrsg. von Ralf Pröve und Carmen Winkel, Göttingen 2012, S. 25-44, hier: S. 29-33.

3 Eugen von Frauenholz, Geschichte des Königlich Bayerischen Heeres von 1867 bis 1914, München 1931, S. 61. Das Protokoll, das hierbei eingehalten werden musste, ist abgedruckt ebd., Anlage X, S. 589.

4 HSTA-KA MKr 11530 Geheime Gesellschaften, 1814-1920; HSTA-KA A XIII 2, Bd. 1 Justiz und Polizei: Geheime Gesellschaften, 1751-1816.

5 Regierungs- (und Intelligenz-) Blatt für das Königreich Bayern, München 1814, Stück 59: Erneuerung des Verbots geheimer Gesellschaften und Verbindungen betr. vom 13. September 1814, S. 1521.

6 Hinweise zur Aktenüberlieferung zum Illuminateneid für Beamte finden sich bei Ludwig Hammermayer, der betont, dass das einschlägige Material zum Illuminateneid, das in München und regionalen staatlichen wie geistlichen Archiven zu finden ist, bisher noch nicht genügend erschlossen sei. Ludwig Hammermayer, Illuminaten in Bayern. Zu Geschichte, Fortwirken und Legende des Geheimbundes. In: Der Illuminatenorden (1776-1785/87). Ein politischer Geheimbund der Aufklärungszeit. Hrsg. von Helmut Reinalter, Frankfurt a. M. 1997, S. 21-77, hier S. $61 \mathrm{f}$. 


\section{Illuminaten im bayerischen Heer}

Der vom Ende des 18. Jahrhunderts bis zum Ersten Weltkrieg in Bayern verbindliche Eid gegen geheime Gesellschaften basierte auf dem Wirken des Illuminatenordens im letzten Drittel des 18. Jahrhunderts. Diese radikal-aufklärerische Vereinigung 7 , die 1774 vom Ingolstädter Professor Adam Weishaupt gegründet wurde und es bis zu ihrer Auflösung 1785 über die bayerischen Landesgrenzen hinaus auf etwa 2000 Mitglieder brachte ${ }^{8}$, hatte auch unter den bayerischen Offizieren viele Anhänger'. Nach Hermann Schüttler waren zum Beispiel in München zwölf Prozent, in Ingolstadt 14 Prozent der bekannten Illuminaten Offiziere. Alle fünf Professoren der Marianischen Landes-Akademie, der Nachfolgerausbildungsstätte des zwischen 1778 und 1789 aufgelösten bayerischen Kadettenkorps, waren Ordensmitglieder ${ }^{10}$. Insgesamt befinden sich unter den 1255 von Hermann Schüttler aufgelisteten Namen 66 Offiziere der kurpfalzbayerischen Armee. Dies entspricht einem Anteil von 5,3 Prozent, doch ist dabei in Rechnung zu stellen, dass auch Ordensangehörige außerhalb

7 Es existiert eine Vielzahl an Studien zum Illuminatenorden. Vgl. als Einstieg bezüglich der neueren Arbeiten zu den Illuminaten mit jeweils ausführlichen Literaturverzeichnissen Monika Neugebauer-Wölk, Debatten im Geheimraum der Aufklärung. Konstellationen des Wissensgewinns im Orden der Illuminaten. In: Die Aufklärung und ihre Weltwirkung. Hrsg. v. Wolfgang Hardtwig, Göttingen 2010, S. 17-46; dies., Esoterische Bünde und bürgerliche Gesellschaft. Entwicklungslinien zur modernen Welt im Geheimbundwesen des 18. Jahrhunderts, Göttingen 1995; Aufklärung und Esoterik. Hrsg. von Monika Neugebauer-Wölk, Hamburg 1999; Stephan Gregory, Wissen und Geheimnis. Das Experiment des Illuminatenordens, Frankfurt a.M., Basel 2009; Hermann Schüttler, Die Mitglieder des Illuminatenordens 1776-1787/93, München 1991.

8 Vgl. Schüttler, Mitglieder (wie Anm. 7), S. 10, der hier seine eigene Schätzung der Mitgliederzahl begründet und daneben auch die davon abweichenden Angaben der älteren Forschung diskutiert.

9 In den meisten Arbeiten wird nur sporadisch auf die Mitgliedschaft von bayerischen Militärangehörigen im Orden und deren langfristige Auswirkungen eingegangen. Direkt mit bayerischen Militärangehörigen, die im Illuminatenorden aktiv waren, beschäftigt sich lediglich die unveröffentlichte Diplomarbeit von Andreas Jungmann, Das Trauma von der Verschwörung - Illuminaten und Militär, unveröffentlichte Diplomarbeit, München 1992. (Ein Exemplar befindet sich in der Bibliothek des Zentrums für Militärgeschichte und Sozialwissenschaften der Bundeswehr in Potsdam.) Vgl. allgemein die für Bayern wichtigsten Arbeiten, in denen kurz auch auf das Militär eingegangen wird, Michael Schaich, Staat und Öffentlichkeit im Kurfürstentum Bayern der Spätaufklärung, München 2001, bes. S. 215-283; Hammermayer, Illuminaten in Bayern (wie Anm. 6); Richard van Dülmen, Der Geheimbund der Illuminaten. Darstellung, Analyse, Dokumente, Stuttgart, Bad Cannstadt 1975; Eberhard Weis, Der Illuminatenorden (1776-1786). Unter besonderer Berücksichtigung der Fragen seiner sozialen Zusammensetzung, seiner politischen Ziele und seiner Fortexistenz nach 1786. In: Aufklärung und Geheimgesellschaften. Zur politischen Funktion und Sozialstruktur der Freimaurerlogen im 18. Jahrhundert. Hrsg. von Helmut Reinalter, München 1989, S. 87-108; Vgl. zu den älteren Arbeiten Ludwig Wolfram, Die Illuminaten in Bayern und ihre Verfolgung. Auf Grund aktenmässigen Befundes dargestellt, 2 Tle., Erlangen 1899-1900; Leopold Engel, Geschichte des Illuminatenordens. Ein Beitrag zur Geschichte Bayerns, Berlin 1906.

10 Bernhard Poten, Geschichte des Militär-Erziehungs- und Bildungswesens in den Landen deutscher Zunge, Bd. 1, Berlin 1889, S. 69-75; Joachim Thielen, Das Militär, die Aufklärung und ihre Gegner. Zwei Beispiele aus dem bayerischen Heer. In: Die Kriegskunst im Lichte der Vernunft. Militär und Aufklärung im 18. Jahrhundert. Hrsg. von Daniel Hohrath und Klaus Gerteis, Teil 2, Hamburg 2000, S. 49-71, hier S. 53. 
Bayerns aufgeführt sind ${ }^{11}$. Eberhard Weis' Auswertung eines Mitgliederverzeichnisses der bayerischen Illuminaten, das 295 Namen umfasst und aus den Akten der vom Kurfürsten eingesetzten Untersuchungskommission stammt, zählt 29 Offiziere. Ihr Anteil an der Gesamtmitgliederzahl beträgt 9,8 Prozent ${ }^{12}$.

Trotz des bedeutsamen quantitativen Anteils der militärischen Führer im Geheimbund waren ihr Einfluss im Orden und jener, der durch Illuminaten in der bayerischen Armee ausgeübt wurde, wohl eher mäßig. Der Großteil der Offiziere und Militärbeamten waren nach den jetzigen Erkenntnissen einfache Mitglieder ${ }^{13}$. Gehobene Positionen erreichten zum Beispiel Leutnant Friedrich Meinhard von Ow (1757-1813), der die Position eines Illuminatus maior innehatte ${ }^{14}$, oder der Regimentsauditor Ferdinand Joseph Maximilian Freiherr von Meggenhofen (1760-1790), der Chef der Illuminatenloge in Burghausen war $^{15}$. Mit Sicherheit kann gesagt werden, dass adlige und bürgerliche Beamte und Geistliche insgesamt für den Illuminatenbund wichtiger waren als Offiziere $^{16}$, was an der Zielsetzung des Ordens lag. Dieser strebte offiziell die Errichtung eines Bildungssystems an, das im Sinne der Aufklärung der Moralität im Menschen zum Durchbruch verhelfen, Unterdrückung und Aberglauben tilgen und den Menschen zur Selbstbestimmung führen sollte ${ }^{17}$. Alle Mitglieder des Ordens waren hierüber unterrichtet. Daneben hatte der Geheimbund aber auch eine politische Zielsetzung, über die nur die höchsten Grade Bescheid wussten. Er strebte nach unmittelbarem politischen Einfluss in allen Territorien des Reichs, um ein Sittenregiment zu errichten, das die Gesellschaft, den Staat und die Kirche unter die Vernunft zu stellen versuchte ${ }^{18}$. Um die politischen Machtverhältnisse zugunsten der Illuminaten zu verändern, griff der Orden zu der Strategie der Unterwanderung. Über eine gezielte Personalpolitik sollte der Zugriff auf Entscheidungspositionen in der Umgebung von Fürsten, an Universitäten, Schulen, in Behörden und Kirchen erlangt werden. Dieser >Marsch durch die Institutionen war in Bayern sehr erfolgreich und verschaffte dem Bund innerhalb weniger Jahre breite Einflussmöglichkeiten auf politische Entscheidungen und Entscheidungsträger ${ }^{19}$. Es gelang dem Or-

11 Schüttler, Mitglieder (wie Anm. 7); vgl. hierzu auch Jungmann, Trauma (wie Anm. 9), S. $30 \mathrm{f}$.

12 Weis, Illuminatenorden (wie Anm. 9), S. 97 f.

13 Vgl. Schüttler, Mitglieder (wie Anm. 7).

14 Schüttler, Mitglieder (wie Anm. 7), S. 114; Jungmann, Trauma (wie Anm. 9), S. 80-82.

15 Vgl. hierzu Ferdinand Joseph Maximilian von Meggenhofen, Meine Geschichte und Apologie. Ein Beitrag zur Illuminatengeschichte, o. O. 1786; Uwe Puschner, »Meggenhofen, Ferdinand Freiherr von«. In: Neue Deutsche Biographie 16 (1990), S. 612 f. Onlinefassung unter <http:// www.deutsche-biographie.de/pnd120872439.html> (5. August 2015).

16 Van Dülmen, Geheimbund (wie Anm. 9), S. 32; Jungmann, Trauma (wie Anm. 9), S. 88.

17 Über ein einheitliches Erziehungskonzept und eine eindeutige ideologische Orientierung verfügte er nicht. Manfred Agethen, Geheimbund und Utopie. Illuminaten, Freimaurer und deutsche Spätaufklärung, München 1984, S. 173.

18 Christoph Hippchen, Zwischen Verschwörung und Verbot. Der Illuminatenorden im Spiegel deutscher Publizistik (1776-1800), Köln 1998, S. 16; van Dülmen, Geheimbund (wie Anm. 9), S. 98.

19 Hippchen, Zwischen Verschwörung und Verbot (wie Anm. 18), S. 10; Reinhart Koselleck, Kritik und Krise. Ein Beitrag zur Pathogese der bürgerlichen Welt, Frankfurt a. M. 1979, S. 76. 
den, insbesondere zentrale Behörden in München wie die Hofkammer und den Hofrat, die Akademie der Wissenschaften und das Zensurkollegium zu einem beträchtlichen Anteil zu unterwandern ${ }^{20}$. Gleichzeitig zielte der Illuminatenbund seit 1782 auf eine Infiltration der Freimaurerlogen, in denen sich der Hochadel, Honoratioren und Staatsdiener in großer Zahl befanden ${ }^{21}$, und auf eine Steuerung der Publizistik und Organisationen, welche die Meinungsbildung der Öffentlichkeit direkt oder indirekt beeinflussten, wie etwa Lesegesellschaften, Buchhandlungen und Verlage ${ }^{22}$.

Insgesamt ist auffällig, dass die Unterwanderung des Militärs in der Zielsetzung des Ordens keine zentrale Rolle spielte, sondern der Illuminatenorden vor allem in Staat, Kirche, Wissenschaft und der öffentlichen Meinung nach Einfluss strebte ${ }^{23}$. Hierzu passt auch, dass der Hofkriegsrat ${ }^{24}$ nach dem jetzigen Forschungsstand wohl nicht mit Illuminaten besetzt wurde ${ }^{25}$. Eine gezielte Infiltration unternahm der Geheimorden allerdings bei der Nachfolgerinstitution des Kadettenkorps, der Marianischen Landesakademie. Wenn auch deren Leiter, Oberst d'Ancillon, kein Illuminat war, so waren doch alle Professoren Geheimbundmitglieder und gehörten dem so genannten patriotischen Flügel an. Ihr Ziel war es, die Schüler geistig und sittlich im Sinne des Ordens auszubilden,

Zum Revolutionsbegriff der Illuminaten siehe Ludwig Hammermayer, Illuminaten in Bayern. $\mathrm{Zu}$ Geschichte, Fortwirken und Legende des Geheimbundes. In: Krone und Verfassung. König Max I. Joseph und der neue Staat. Beiträge zur Bayerischen Geschichte und Kunst 1799 bis 1825. Hrsg. von Hubert Glaser, München, Zürich 1980, S. 146-173, hier S. 147, Anm. 14.

20 So waren z. B. im Hofrat neun von 38 Räten Illuminaten, im Zensurkollegium gehörten sogar zehn von zwölf Räten dem Orden an. Agethen, Geheimbund und Utopie (wie Anm. 17), S. 80, $234 \mathrm{f}$.

21 Die Freimaurer hatten gänzlich andere Ziele als der radikal-aufklärerische Illuminatenorden. Sie waren alles andere als eine Bewegung des Umsturzes, wirkten gemeinnützig und lokal und versuchten, die sich im 18. Jahrhundert entwickelnden Ideen der individuellen Freiheit, der Toleranz, der Gleichheit und der Achtung der menschlichen Person über Standes-, Konfessionsund Staatsgrenzen hinweg zu verbreiten. Die Freimaurer opponierten niemals bewusst gegen Kirche und Staat, sondern betonten stets ihre Neutralität bzw. Staatstreue. Agethen, Geheimbund und Utopie (wie Anm. 17), S. 59; Hippchen, Zwischen Verschwörung und Verbot (wie Anm. 18), S. 6; Weis, Illuminatenorden (wie Anm. 9), S. 90.

22 Hippchen, Zwischen Verschwörung und Verbot (wie Anm. 18), S. 10 f.

23 Van Dülmen, Geheimbund (wie Anm. 9), S. 72; ders., Die Gesellschaft der Aufklärer. Zur bürgerlichen Emanzipation und aufklärerischen Kultur in Deutschland, Frankfurt a. M. 1986, S. 106; Weis, Illuminatenorden (wie Anm. 9), S. 104; Hammermayer, Illuminaten in Bayern (wie Anm. 6), S. $22 \mathrm{f}$.

24 Dem 1620 gegründeten Hofkriegsrat oblagen in der Zeit Karl Theodors alle Entscheidungen, die das Kriegswesen und das bayerische Heer betrafen. Im Jahre 1792 wurde zusätzlich der bayerische Generalstab etabliert. Aus dem Hofkriegsrat ging 1799 das Oberkriegskollegium hervor, das nachfolgend innerhalb von kurzer Zeit noch mehrmals umgewandelt wurde. Seit 1808 wurde schließlich in Bayern ein Kriegsministerium eingerichtet, das bis zum Ende der bayerischen Armee Bestand hatte. Gerhard Heyl, Militärwesen. In: Handbuch der bayerischen Ämter, Gemeinden und Gerichte 1799-1980. Hrsg. von Wilhelm Volkert, München 1983, S. 330 393, hier: S. 330-337.

25 Zumindest wird bei Andreas Jungmann, der die Aktenbestände des Kriegsarchivs (HSTA-KA A XIII 2, Bd. 1 (1751-1816): Justiz und Polizei. Geheime Gesellschaften.; HSTA-KA A XIII 2, Bd. 2 (1791-1804): Justiz und Polizei. Geheime Gesellschaften) gesichtet hat, über keinen diesbezüglichen Vorfall berichtet. Aus der Arbeit geht allerdings nicht hervor, wie systematisch die Akten durchgesehen wurden. Jungmann, Trauma (wie Anm. 9), 
um so die künftigen Offiziere für diesen zu gewinnen. Allerdings erfüllten sich die Erwartungen der Illuminaten, die sie an die Mitgliedschaft der dort tätigen Lehrer gestellt hatten, nicht, sondern verkehrten sich stattdessen ins Gegenteil. Bereits Ende 1783 trat der gesamte patriotische Flügel aus dem Geheimbund aus und gerade die Mitglieder aus dem Lehrerkollegium der Herzoglich Marianischen Landesakademie, die diesem Flügel zugerechnet wurden, trugen zur Aufdeckung und Bekämpfung des Ordens bei $^{2{ }^{2}}$. Dessen ungeachtet zeigen die Unterwanderung der Marianischen Landesakademie wie auch die Aufnahme vieler Offiziere, dass der Wille vorhanden war, auch in der Armee Einfluss zu gewinnen. Hierfür spricht auch, dass das Militär durch seine unmittelbare Bindung an den Landesherrn eine wichtige Stütze des Throns war und die Stabsoffiziere und die Generalität der Hofgesellschaft angehörten, wodurch sie zur direkten Umgebung des Kurfürsten Zugang hatten ${ }^{27}$.

Bisher fehlen Studien darüber, was Offiziere zur Mitgliedschaft im Illuminatenorden motivierte. Von der Forschung sind allgemein drei Beweggründe für den Eintritt in den Illuminatenbund herausgearbeitet worden. Hier ist einmal das Streben nach >Erleuchtung $<$ zu nennen, da die Kirchen an Glaubwürdigkeit in zunehmendem Maße eingebüßt hatten und der Geheimorden mit einer Art von Alternativkirche aufwartete. Als zweites ermöglichte der Illuminatenbund einen geheimen und privaten Freiraum, in dem abseits der absolutistischen Ständegesellschaft Selbstverwirklichung möglich war. Der Orden hielt ein großes Bildungsangebot bereit, das viele Mitglieder auch nach dessen Auflösung als für ihre Selbstbildung und Wissensvermittlung höchst anregend beschrieben ${ }^{28}$. Gerade mit der Vergrößerung des Illuminatenbundes ähnelte dieser auf den unteren Ebenen zunehmend einer gelehrten Gesellschaft $^{29}$. Schließlich hofften die Mitglieder, gesellschaftspolitische Wirkung im

26 Ab 1785 veröffentlichten sie so genannte Enthüllungsschriften über die kosmopolitischen und antireligiösen Ziele der Illuminaten, was zur Aufdeckung der Machenschaften des Ordens beitrug und dem Ansehen des Ordens und seiner Anhänger deutlich schadete. Horst Erlich, Die Kadettenanstalten. Strukturen und Ausgestaltung militärischer Pädagogik im Kurfürstentum Bayern im späteren 18. Jahrhundert, München 2007, S. 146, 148.

27 Vgl. hierzu Uta Krottenthaler, Eine militärische Elite zwischen Stagnation und Wandel. Die bayerische Generalität im Übergang von der Frühen Neuzeit zur Moderne am Beispiel ihres Karriereverlaufs. In: Militärische Eliten in der Frühen Neuzeit. Hrsg. von Gundula Gahlen und Carmen Winkel, Potsdam 2010, S. 85-126, bes. S. 125 f.; Stefanie Buchhold, Johann Nepomuk Graf von Triva (1755-1827) und die bayerische Heeresreform nach 1804, München 2012, bes. S. 114, 163. Jungmann geht hingegen davon aus, dass die Attraktivität für den Orden, in diesem Bereich starke Einflüsse zu gewinnen, nicht besonders groß war, da das bayerische Militär unter Karl Theodor im Vergleich etwa zu Preußen nur eine untergeordnete Stellung innehatte. Jungmann, Trauma (wie Anm. 9), S. 88.

28 Van Dülmen, Die Gesellschaft der Aufklärer (wie Anm. 23), S. 111.

29 Dies zielte darauf, den Zeitgenossen einerseits die wahren Absichten des Illuminatenbundes zu verschleiern. Andererseits sah es der Illuminatenorden auf seinen unteren Ebenen als notwendig an, die aufklärerische Bildung der Neuzugänge zu erhöhen und damit ihre sittliche und moralische Erziehung zu verbessern. Erst in einem weiteren Schritt sollten sie dann für den Orden tätig werden. Norbert Schindler, Der Geheimbund der Illuminaten. Aufklärung, Geheimnis und Politik. In: Freimaurer und Geheimbünde im 18. Jahrhundert in Mitteleuropa. Hrsg. von Helmut Reinalter, Frankfurt a. M. 1993, S. 284-318, hier S. 297; Agethen, Geheimbund und Utopie (wie Anm. 17), S. 173. 
absolutistischen Staat zu erzielen, der solchen Bemühungen ansonsten nur sehr wenig Raum ließ ${ }^{30}$. Ganz allgemein wurden Geheimgesellschaften im 18. Jahrhundert als wichtige Medien aufklärerischer Tätigkeit und Emanzipation angesehen, da in ihnen wirksamer Einfluss unter großem Schutz möglich schien $^{31}$.

Einiges deutet darauf hin, dass sich dem Illuminatenorden vorrangig Offiziere mit gehobener Bildung anschlossen, auch wenn das Offizierskorps in Kurpfalzbayern insgesamt lediglich über einen sehr sgemischten< Bildungsstand verfügte ${ }^{32}$. Zum einen kam der Orden vorrangig den Wünschen der sich auch in Bayern formierenden bürgerlich-adligen Intelligenzschicht entgegen ${ }^{33}$. Zum anderen sprechen hierfür die Namen von einigen bekannten Illuminaten aus dem Kreis kurpfalzbayerischer Offiziere und Militärbeamter, wenn auch diese sicherlich nicht repräsentativ für alle Illuminaten der bayerischen Armee waren. Aufzuführen wären hier neben den schon erwähnten Ferdinand Freiherr von Meggenhofen und Friedrich Meinhard von Ow, der Hauptmann Johann Maximilian Reichsgraf von Preysing-Hohenaschau im Moos ${ }^{34}$, Major Johann Nepomuk von Triva ${ }^{35}$ und der Ingenieur-Hauptmann Sebastian Heinrich von $\mathrm{Hande}^{36}$, die alle einfache Mitglieder im Illuminatenorden waren. Sie vereinte durchweg eine überdurchschnittliche Bildung, und einige von ihnen machten herausragende Karrieren innerhalb der bayerischen Armee ${ }^{37}$.

\section{Das Vorgehen gegen die Illuminaten und der Illuminateneid unter Kurfürst Karl Theodor (1777-1799)}

Bereits einige Jahre vor der Zerschlagung des Illuminatenordens im Jahre 1785 war dieser kaum mehr handlungsfähig. Streitigkeiten auf der Leitungsebene

30 Ernst-Otto Fehn, Der Illuminatenorden und die Aufklärung. Kritik und Korrektur einer neuen Interpretation. In: Aufklärung, Vormärz, Revolution 7 (1988), S. 6-30, hier S. 9; Daniel Wilson, Geheimräte gegen Geheimbünde. Ein unbekanntes Kapitel der klassisch-romantischen Geschichte Weimars, Stuttgart 1991, S. 21.

31 Van Dülmen, Die Gesellschaft der Aufklärer (wie Anm. 23), S. 111.

32 Oskar Bezzel, Geschichte des kurpfalzbayerischen Heeres von 1778 bis 1803, München 1930, S. 176; ders., Geschichte des Königlich Bayerischen Heeres von 1806 (1804) bis 1825, München 1933, S. 197.

33 Ludwig Hammermayer, Das Ende des alten Bayern. Die Zeit des Kurfürsten Max III. Joseph (1745-1777) und des Kurfürsten Karl Theodor (1777-1799). In: Handbuch der bayerischen Geschichte. Hrsg. von Andreas Kraus, Bd. 2, 2. Aufl., München 1988, S. 1135-1283, hier S. 1191.

34 Er war gleichzeitig Kammerherr und Geheimer Rat sowie Vizepräsident des Hofrates in München. Schüttler, Mitglieder (wie Anm. 7), S. 121.

35 Triva wurde schließlich von 1814-1822 Staatsminister der Armee. Schüttler, Mitglieder (wie Anm. 7), S. 155. Vgl. zur Illuminaten-Mitgliedschaft Nepomuk von Trivas ausführlich Buchhold, Triva (wie Anm. 27), S. 96-100.

36 Er stieg unter Max Joseph bis zum Generalleutnant auf und wurde der Chef des Ingenieurkorps. Schüttler, Mitglieder (wie Anm. 7), S. 67.

37 Jungmann, Trauma (wie Anm. 9), S. 86. 
über seine Ziele und Mängel in der Organisation, die der Führung keine Übersicht und Kontrolle erlaubte, hatten seinen Niedergang eingeleitet ${ }^{38}$.

Die Aufhebung des Ordens war dann mit der politischen Krise verbunden, die das Bekanntwerden von Plänen des Kurfürsten Karl Theodor auslöste, Ober- und Niederbayern gegen die habsburgischen Niederlande einzutauschen. In die Vorbereitungen war der Illuminatenbund involviert, weswegen ein Teil der Mitglieder, der sogenannte patriotische Flügel, von dem schon in Bezug auf die Marianische Landesakademie die Rede war, den Orden im Dezember 1783 und im Januar 1784 verließ. Hierdurch wurde die Absicht des Ländertauschs in die bayerische Öffentlichkeit getragen, was offene Feindseligkeit der Bevölkerung gegenüber dem Landesherrn zur Folge hatte ${ }^{39}$.

In dieser brisanten Situation kamen immer mehr Details über die vom Orden betriebene protektionistische Personalpolitik und die Unterwanderung der staatlichen Schaltstellen ans Licht. Hinzu kamen spektakuläre Vorfälle wie der angebliche Raub geheimer Dokumente aus dem kurfürstlichen Archiv, der den Illuminaten angelastet wurde. All dies schuf eine Atmosphäre, die dem Kurfürsten und seinen Beratern die Illuminaten als hochgradig gefährlich erscheinen ließ ${ }^{40}$.

Am 22. Juni 1784 verbot Karl Theodor, der selbst 25 Jahre lang Freimaurer gewesen war $^{41}$, per Edikt sämtliche ohne landesherrliche Bestätigung gegründeten Geheimgesellschaften, wobei er die Illuminaten noch nicht beim Namen nannte ${ }^{42}$. Im zweiten Mandat vom 2. März 1785 verwendete er dann ausdrücklich den Namen der Illuminaten und untersagte ihnen jede Versammlung ${ }^{43}$. Der Geheimbund gehorchte in Bayern dieser kurfürstlichen Verordnung. Im April 1785 löste Graf Johann Martin von Stolberg-Rossla, welcher der Nationalobere des Ordens und der Nachfolger Weishaupts war, in Neuwied den Illuminatenbund auf und entband alle Mitglieder von ihren Verpflichtungen ${ }^{44}$. Nach der Auflösung erhielt Karl Theodor immer stärkeren Einblick in die Ordensangelegenheiten und reagierte mit Erlassen gegen Geheimgesellschaf-

38 Eberhard Weis, Deutschland und Frankreich um 1800. Aufklärung - Revolution - Reform. Hrsg. von Walter Demel und Bernd Roeck, München 1990, S. 46-66, hier S. 21; Hippchen, Zwischen Verschwörung und Verbot (wie Anm. 18), S. 12.

39 Karl Otmar von Aretin, Bayerns Weg zum souveränen Staat. Landstände und konstitutionelle Monarchie 1714-1818, München 1976, S. 64-119; zusammenfassend Weis, Illuminatenorden (wie Anm. 9), S. 96 f.

40 Hippchen, Zwischen Verschwörung und Verbot (wie Anm. 18), S. 13.

${ }^{41}$ Weis, Illuminatenorden (wie Anm. 9), S. 89.

42 Die Verordnung vom 22.6.1784, die sich gegen»Kommunitäten, Gesellschaften, und Verbrüderungen, als eine an sich schon verdächtige, und gefährliche Sache « richtete, ist abgedruckt bei Wolfram, Illuminaten in Bayern (wie Anm. 9), Bd. 2, S. 6.

43 Das Verbot ist abgedruckt in der Sammlung der Churpfalz-Baierischen allgemeinen und besonderen Landes-Verordnungen von Sr. Churfürstl. Durchläucht Maximilian Joseph IV. in Justiz-, Finanz-, Landschafts-, Mauth-, Polizey-, Religions-, Militär- und vermischten Sachen, Teil 4, München 1785, Nr. 7.

${ }_{44}$ Hingegen existierten in einigen Städten, etwa in Salzburg und Gotha, Illuminatenlogen weiterhin. Hippchen, Zwischen Verschwörung und Verbot (wie Anm. 18), S. 13. 
ten in den Jahren 1785, 1787 und 1790, die darauf zielten, den Illuminatenbund zu zerschlagen und die Beteiligten ausfindig zu machen ${ }^{45}$.

Bezeichnend ist, dass sich der Landesherr in seinen ersten Schritten, die er 1785 unternahm, um den Herrschaftsapparat vom Einfluss der Illuminaten zu reinigen, direkt an das Militär wandte. Im ersten Erlass vom 3. August 1785, den der Hofkriegsrat am 11. August an das Heer weiterleitete, verlangte Karl Theodor von denjenigen seiner Offiziere, welche Illuminaten gewesen waren, sich innerhalb von sechs Wochen in einem schriftlichen Revers vom Orden loszusagen und sicherte ihnen in diesem Fall Straffreiheit zu. Sollte hingegen ein Militärangehöriger den Revers nicht ausstellen und zukünftig als Illuminat enttarnt werden, wurde ihm die sofortige Verhaftung und Entlassung aus dem Militärdienst angedroht. Alle Generale, Gouverneure, Kommandanten und kommandierenden Regimentsoffiziere hatten ihre Untergebenen über den geforderten Revers zu informieren. Dies sollte »obne Erwekung vielen Aufsebens in möglicher Stille " geschehen ${ }^{46}$. Der Erlass führte dazu, dass Illuminaten im bayerischen Militär in großer Zahl die geforderte schriftliche Erklärung abgaben. Der erste Revers findet sich bereits mit Datum vom 12. August 1785, einen Tag nach dem Erlass ${ }^{47}$. Nicht auf das Militär beschränkt sondern an alle in königlichen Diensten stehenden Personen gerichtet war das darauf folgende Mandat gegen die Illuminaten, das am 16. August 1785 erlassen wurde und in ähnlicher Weise den Mitgliedern des Ordens den schriftlich zu erklärenden Austritt befahl ${ }^{48}$.

Im September 1785 wurde an alle Offiziere, die sich schriftlich von den Illuminaten distanziert und damit zu ihrer früheren Mitgliedschaft bekannt hatten, ein Fragebogen mit 26 Punkten ausgegeben. Dieser zielte darauf, Informationen über die Binnenstruktur und die Zusammensetzung des Illuminatenordens zu erhalten. Inwieweit die Antworten ausgewertet und verwendet wurden, ist allerdings nicht überliefert ${ }^{49}$.

Dass die Militärangehörigen zuerst die Aufforderung erhielten, sich vom Illuminatenorden zu distanzieren und die sich hier bekennenden Illuminaten zusätzlich zum Revers noch einen Fragebogen beantworten mussten, sind Belege dafür, dass der Landesherr eine enge Verbindung zu seiner Armee hatte und sie als eine besonders wichtige Stütze seiner Herrschaft ansah ${ }^{50}$.

45 Agethen, Geheimbund und Utopie (wie Anm. 17), S. 80.

46 HSTA-KA A XIII 2, Bd. 1 Justiz und Polizei: Geheime Gesellschaften, 1751-1816, Neuerlicher Auftrag an sämmtl. Generäle u. Gouverrneurs hinsichtlich dieses Verbotes vom 3.8.1785.

47 Schaich, Staat und Öffentlichkeit (wie Anm. 9), S. 220 f.

48 Das Verbot ist abgedruckt in der Sammlung der Churpfalz-Baierischen allgemeinen und besonderen Landes-Verordnungen (wie Anm. 43), Teil IV, Nr. 89.

49 Auch ist nichts darüber bekannt, wie lange Offiziere noch den Fragebogen auszufüllen hatten und ob hiervon ehemalige Illuminaten, die erst im September 1785 den Revers ausstellten, betroffen waren. Schaich, Staat und Öffentlichkeit (wie Anm. 9), S. 223. Der Fragebogen ist in zweifacher Form, einmal unausgefüllt und einmal mit Meggenhofens Antworten versehen, abgedruckt in seiner Autobiographie. Meggenhofen, Meine Geschichte (wie Anm. 15), S. 43-72.

50 Siehe auch die Einschätzung von Schaich, Staat und Öffentlichkeit (wie Anm. 9), S. 220. Hinzu kommt, dass für den Landesherrn der direkte Zugriff auf die einzelnen Offiziere wie auch auf die landesherrlichen Beamten besonders einfach war, weil keine Zwischeninstanzen wie etwa bei den landständischen Beamten bestanden. Die Offiziere waren bei jedem Zugang und jeder 
Und Karl Theodor wurde hier in seinen Erwartungen nicht enttäuscht. Die bayerischen Offiziere kamen beim Verbot des Illuminatenbundes und der Verordnung von 1785 durchgängig dem Willen des Landesherrn nach. Die Loyalität zum Kurfürsten erwies sich als weit wichtiger als jene zum Orden. Die Offiziere waren nicht bereit, für diesen die eigene Laufbahn beim Militär zu gefährden ${ }^{51}$, wie die von Andreas Jungmann untersuchten Fälle sehr deutlich zeigen ${ }^{52}$. Gerade bei militärischen Führern, die sich in den 1790 er Jahren vom Orden lossagen sollten, war der Illuminatenbund in ihrer Wahrnehmung längst Geschichte, und sie waren nicht gewillt, seinetwegen Opfer zu bringen ${ }^{53}$.

Im Hinblick auf die Verfolgungs- und Strafpraxis bei verdächtigen Offizieren belegen die von Jungmann ausgewerteten Fälle, dass der Kurfürst bei Militärangehörigen ähnlich wie bei Beamten keine echten Verfolgungen durchführte und stattdessen eine milde Linie verfolgte. Offiziere konnten sich vor weiteren Verfolgungen schützen, indem sie ihre Loyalität gegenüber dem Landesherrn bekundeten, Reue zeigten und sich eindeutig vom Illuminatenorden distanzierten. Karl Theodor war dabei im Allgemeinen sehr gutgläubig gegenüber ihren Aussagen ${ }^{54}$.

Selbst wenn er teilweise Drohungen aussprach, an Offizieren Exempel statuieren zu wollen, blieb er in der Höhe der Bestrafung in der Regel unter den Empfehlungen des Hofkriegsrats. Häufig beließ er es bei Verweisen und milderte Urteile ab. Hatte er Strafen ausgesprochen, führte er nachfolgend rasche Begnadigungen durch. Auch die untypische Verhaftung und Verurteilung des Regimentsauditors, Ferdinand Freiherr von Meggenhofen (1760-1790), der 1785 ohne Gerichtsverfahren auf unbestimmte Zeit in ein Kloster gebracht wurde, um dort »in christkatholischen Sitten- und Glawbenslebren der Nothdurft nach unterrichtet « zu werden ${ }^{55}$, zeigt, da er nach wenigen Wochen bereits begnadigt wurde, nur eine halbherzige Bereitschaft zur Verfolgung von Illuminaten im Militär ${ }^{56}$.

Ebenso wie bei verdienten Beamten sah der Landesherr es auch bei Offizieren als ungehörig und für das Ansehen schädlich an, zu Verfolgungs- und

Beförderung auf das Wohlwollen des Landesherrn angewiesen. Zus. Gundula Gahlen, Das bayerische Offizierskorps 1815-1866, Paderborn u. a. 2011, S. 119. Dies blieb auch während des gesamten 19. Jahrhunderts der Fall, wohingegen in Bayern die höheren Beamten seit der Neuordnung des bayerischen Staates eine Dienstpragmatik besaßen, die sie in vielerlei Hinsicht vor landesherrlicher Willkür schützte. Vgl. hierzu ausführlich Bernd Wunder, Privilegierung und Disziplinierung. Die Entstehung des Berufsbeamtentums in Bayern und Württemberg (17801825), München, Wien 1978, S. 19-234.

51 Vgl. van Dülmen, Geheimbund (wie Anm. 9), S. 92; Jungmann, Trauma (wie Anm. 9), S. 87.

52 Jungmann, Trauma (wie Anm. 9), S. 45-85. Sie beziehen sich auf die folgenden Akten HSTA-KA A XIII 2, Justiz und Polizei: Geheime Gesellschaften, Bd. 1 (1751-1816), Bd. 2 (1791-1804).

53 Meggenhofen stellte hier eine Ausnahme dar. Jungmann, Trauma (wie Anm. 9), S. 87 f.

54 Ders., S. 89.

55 Sein autobiographischer Bericht über die Illuminatenverfolgung erreichte eine große Öffentlichkeit. Meggenhofen, Meine Geschichte (wie Anm. 15), S. 76.

56 Jungmann, Trauma (wie Anm. 9), S. 89. Zwei von Hammermayer angeführte Fälle scharfer und existenzschädigender Verurteilungen betrafen keine Armeeangehörigen. Hammermayer, Illuminaten in Bayern (wie Anm. 19), S. 152. 
Strafmaßnahmen zu greifen und hielt sich hier nach Möglichkeit zurück ${ }^{57}$, wobei sicherlich auch eine Rolle spielte, dass viele der Offiziere adelig waren. Auch vermied er so, verdiente militärische Führer zu verlieren, und erreichte stattdessen den Effekt, die Offiziere durch die gezeigte Milde eng an die Krone $\mathrm{zu}$ binden $^{58}$.

Allgemein ist zu betonen, dass bei den einfachen Mitgliedern der Illuminaten auch außerhalb von Militär und Beamtenschaft das angedrohte Strafmaß selten durchgesetzt wurde. Lediglich bei Personen, die in der Ordenshierarchie höher standen, wurde in den Jahren 1785 und 1786 hart vorgegangen ${ }^{59}$. Dass, wie die zeitgenössische Publizistik immer wieder betonte, eine gnadenlose Illuminatenverfolgung stattfand, ist für die gesamtbayerischen Verhältnisse unzweifelhaft übertrieben ${ }^{60}$. Nur in Bezug auf die Publizistik der 1780er und frühen 1790er Jahre kann aufgrund der dort stattfindenden umfassenden Kampagne von einer scharfen Verfolgung gesprochen werden ${ }^{61}$.

Weitere Verbote der Illuminaten erfolgten in Bayern $1787^{62}$ und 1790, wobei 1790 erstmalig der Illuminateneid für zivile und geistliche Staatsdiener, Offi-

57 Agethen, Geheimbund und Utopie (wie Anm. 17), S. 81 f.; Jungmann, Trauma (wie Anm. 9), S. 91.

58 Hier zeigt sich eine Parallele zum Umgang des Königs mit sich duellierenden Offizieren, in denen bei sehr strenger Rechtslage milde Bestrafung und großzügige Begnadigungspraxis der Regelfall waren. Über die Begnadigungspraxis konnte der König seine fortbestehende Souveränität und die persönliche Abhängigkeit der Offiziere vom monarchischen Willen unter Beweis stellen. Vgl. hierzu Gundula Gahlen, Das Duell im bayerischen Offizierskorps im 19. Jahrhundert. In: Das Duell. Ehrenkämpfe vom Mittelalter bis zur Moderne. Hrsg. von Ulrike Ludwig, Barbara KrugRichter und Gerd Schwerhoff, Konstanz 2012, S. 259-273; Friedhelm Guttandin, Das Duell aus sozialwissenschaftlicher Perspektive. In: Jahrbuch der Juristischen Zeitgeschichte 5 (2003), 4, S. 21-36, hier S. 31-33; Peter Dieners, Das Duell und die Sonderrolle des Militärs. Zur preußischdeutschen Entwicklung von Militär- und Zivilgewalt im 19. Jahrhundert, Berlin 1992, S. 111 f. Vgl. hierzu allgemein Friedhelm Guttandin, Das paradoxe Schicksal der Ehre. Zum Wandel der adeligen Ehre und zur Bedeutung von Duell und Ehre für den monarchischen Zentralstaat, Berlin 1992.

59 Dabei erregte von aufklärerischer Seite insbesondere Kritik, dass die Obrigkeit sich nicht an die gültigen Rechtsnormen hielt und gerichtliche Untersuchungen meist nicht durchgeführt wurden. Stattdessen sprach der Landesherr in absolutistischer Tradition Erlasse aus, in denen er die Betroffenen mit Exil, Gefängnis, Versetzungen oder Einkommenseinbußen belegte. Hippchen, Zwischen Verschwörung und Verbot (wie Anm. 18), S. 15.

60 Dies hebt vor allem Hammermayer hervor. Hammermayer, Illuminaten in Bayern (wie Anm. 19), S. $150-153$ und S. $164 \mathrm{ff}$.

61 Vgl. hierzu ausführlich Hippchen, Zwischen Verschwörung und Verbot (wie Anm. 18). Trotz dieser Relativierungen sei abschließend noch betont, dass in anderen Territorien - etwa in den Kurfürstentümern Köln und Mainz - überhaupt keine Illuminatenverfolgungen stattfanden. Hier blieben die Verfolgungen aus, da die geistlichen Kurfürsten sowie viele ihrer Domkapitulare dem Illuminatenorden angehört oder nahegestanden hatten. Allerdings wurde in Köln 1793, als der Orden längst aufgehört hatte zu existieren, ein allgemeines Verbot von Geheimgesellschaften erlassen. Edmund Nacken, Die Minervalkirche von Stagira. Zur Geschichte des Illuminatenordens im kurfürstlichen Bonn. In: Bonner Geschichtsblätter 1 (1937), S. 167-175; Weis, Illuminatenorden (wie Anm. 9), S. 93; van Dülmen, Geheimbund (wie Anm. 9), S. 61; Karl Härter, Reichstag und Revolution 1789-1806. Die Auseinandersetzung des immerwährenden Reichstags zu Regensburg mit den Auswirkungen der Französischen Revolution auf das Alte Reich, Göttingen 1992, S. 374 f.

62 Sammlung der Churpfalz-Baierischen allgemeinen und besonderen Landes-Verordnungen (wie Anm. 43), Teil IV, 1787, Nr. 1044. 
ziere und Militärbeamte eingeführt wurde. Diese nachfolgenden Verbote lagen darin begründet, dass Gerüchte von einem Fortbestand der Illuminaten nach der Aufhebung und Zerschlagung des Bundes in Bayern nicht abebbten. $\mathrm{Zu}-$ dem bewirkten die Französische Revolution von 1789 und der Beginn des siegreichen Vordringens der Franzosen in das Reich, dass ähnliche Entwicklungen auch in Bayern befürchtet wurden. Konservative Kreise sahen den Illuminatenorden wie auch andere geheime Gesellschaften als Feinde der alten Ordnung und als Inkarnation der aufklärerischen Verschwörung gegen die Grundfesten von Staat, Religion und Gesellschaft an. Die Geheimbünde wurden für die Ausbreitung aufklärerischen, liberalen und revolutionären Gedankengutes und der >neuen französischen Grundsätzeく verantwortlich gemacht. Sollten sich diese Ideen auch bei den zivilen, geistlichen und militärischen Amtsträgern verbreiten, wurde die Gefahr einer illoyalen Haltung und Entfremdung gegenüber dem Dienstherrn und damit einer Aushöhlung und eines Umsturzes des Herrschaftsgefüges beschworen ${ }^{63}$.

Im gedruckten Erlass von 15. November 1790 zählte Karl Theodor ausführlich auf, welche Befürchtungen mit dem Verbot der geheimen Gesellschaften verbunden waren, welche Aktivitäten des Illuminatenordens zur Zeit noch liefen und welche Strafen verhängt wurden ${ }^{64}$. Der Erlass ist ganz im Geist der Gegenaufklärung geschrieben. Bezeichnend ist, dass darin die Bedrohungen, die von den Illuminaten für die Religion ausgingen, mehr Platz einnahmen als jene, denen der Staat ausgesetzt war ${ }^{65}$. Den Mitgliedern wurde vorgeworfen, »in ibren Versammlungen gegen die Religion, den Staat und die Regierung die gefährlichsten Projekte [zu] schmieden «. Dass Religion, Staat und Regierung in einem Atemzug genannt wurden, ist damit zu erklären, dass Bayern bis Anfang des 19. Jahrhunderts ein rein katholisches Land und der Katholizismus Staatsreligion war ${ }^{66}$.

In Punkt sechs wurde speziell auf Geistliche, Beamte und Offiziere eingegangen und verlautet: »in Fällen, wenn sie zu geistlichen oder weltlichen, Militärund Civil-Ämtern befördert werden, ibre verdammten Grundsätze noch mebr verbreiten können; so erklären Wir andurch, daß Wir keinen mebr [...] weder auf eine Bedienung, oder Pfriende mebr anstellen, noch zu einer bessern oder

63 Hippchen, Zwischen Verschwörung und Verbot (wie Anm. 18), S. 15 f.; van Dülmen, Geheimbund (wie Anm. 9), S. 93; Weis, Illuminatenorden (wie Anm. 9), S. 106 f.; Härter, Reichstag (wie Anm. 61), S. 359-361.

${ }_{64}$ HSTA-KA A XIII 2, Bd. 1 Justiz und Polizei: Geheime Gesellschaften, 1751-1816, Edikt Karl Theodors vom 15.11.1790. Das Edikt ist abgedruckt bei van Dülmen, Geheimbund (wie Anm. 9), S. 411-413.

65 So auch Schaich, Staat und Öffentlichkeit (wie Anm. 9), S. 350 f.

66 Das katholische Bekenntnis war die Bedingung, sich in Bayern ansässig zu machen. Aufgrund der religiös fundierten Staatsordnung galten Religion wie auch Moral als die beiden Pfeiler, auf denen das Gemeinwesen beruhte. Entsprechend wurde ein Angriff auf die Religion als eine Unterminierung und Zerrüttung der staatlichen Ordnung gewertet, da so der Zusammenhalt innerhalb des Gesellschaftsverbandes und die Bindung der Untertanen an den Landesherrn gelockert würden. Schaich, Staat und Öffentlichkeit (wie Anm. 9), zus. S. 1, 416; Christian Lankes, München als Garnison im 19. Jahrhundert. Die Haupt- und Residenzstadt als Standort der Bayerischen Armee von Kurfürst Max IV. Joseph bis zur Jahrhundertwende, Berlin 1993, S. 601 . 
böhern Stelle vorrucken lassen werde. "Hier wurde deutlich gemacht, dass neben den staatlichen und geistlichen Ämtern auch das Militär als ein Ort angesehen wurde, der die Möglichkeit bot, auf viele Personen Einfluss auszuüben.

Im achten Punkt wurde der Illuminateneid eingeführt, der eigentlich einen Anti-Illuminateneid darstellte ${ }^{67}$. Jeder Beamte, Geistliche oder Offizier hatte vor der Ablegung seines Diensteides von nun an diesen zu schwören und bei jeder Beförderung oder Versetzung zu wiederholen, da aufgrund der Verstellungskunst der Illuminaten dies der einzige Weg sei, ihrem Zugang Einhalt zu gebieten. Der Kandidat musste beschwören, »daß er weder jemals ein Mitglied der Illuminaten noch einer andern vergleichbaren, wie immer genannten, Sekte gewesen, noch zur Zeit sey, auch in Zukunft zu keiner derselben treten werde."Bei Falschaussage sollten ein Kriminalprozess wegen Eidbruch und eine Entlassung aus den königlichen Diensten erfolgen.

Im August 1791 wurden die Bestimmungen so konkretisiert, dass verschiedene Schwurformeln für all jene, die nie Illuminaten waren, und für ehemalige Angehörige des Bundes bestimmt wurden. Letztere hatten sich in der Schwurformel jetzt und in Zukunft vom Orden zu distanzieren ${ }^{68}$.

Damit hatten alle bayerischen Offiziere und Militärbeamte neben ihrem Fahneneid, in dem sie Treue und Gehorsam gegenüber dem Landesherrn gelobten $^{69}$, den Eid gegen geheime Gesellschaften zu schwören. Alle bayerischen weltlichen und geistlichen Zivilstaatsdiener, seien es Beamte oder öffentliche Diener, mussten bei ihrer Dienstverpflichtung seit 1818 sogar drei Eide schwören: denjenigen auf die Verfassung, die Verpflichtung für den betreffenden Dienst und denjenigen gegen geheime Gesellschaften ${ }^{70}$. Letzterer diente der

67 Vgl. zum Begriff Dietz-Rüdiger Moser, Karl Theodor. Der Kurfürst und die Schönen Künste. In: Die Herrscher Bayerns. 25 historische Portraits von Tassilo III. bis Ludwig III. Hrsg. von Alois Schmid und Katharina Weigand, München 2001, S. 279-294, hier S. 291.

68 Der Wortlaut der verschiedenen Schwurformeln ist abgedruckt bei J. Franz, Die Abschwörung des Illuminateneides. In: Passauer Theologisch-praktische Monatsschrift 19 (1909), S. 253-258. Siehe auch Schaich, Staat und Öffentlichkeit (wie Anm. 9), S. 355 f.

69 Vgl. z. B. den für alle Militärangehörigen bayerischen Fahneneid in der Fassung von 1848, der mit leichten Abwandlungen in der Zeit des Deutschen Bundes gültig war: "Ich schwöre und gelobe Seiner Königlichen Majestät getreu, gewärtig und gehorsam zu sein, wie nicht weniger allen denen, welche von Seiner Königlichen Majestät wegen mir zu befeblen haben, allen gebührenden Gehorsam zu erzeigen, alles was zu Allerhöchstdero Dienstes, ihres Landes und ihrer Unterthanen Woblfahrt gereicht, möglichst und pflichtschuldigst $z u$ befördern, auch wider alle Feinde Seiner Königlichen Majestät ehrlich und mannhaft zu streiten, folglich in allem dasjenige zu thun, was mir vermöge der mir anvertrauten Charge und den damit verbundenen Pflichten zu thun zukömmt. So wahr mir Gott helfe und sein heiliges Wort." HSTA-KA A I 45, Kriegsministerialreskript Nr. 3056 vom 21.3.1848; vgl. daneben leicht abgewandelt DienstVorschriften für die königlich baierischen Truppen aller Waffengattungen, 1. Teil: Allgemeine Dienst-Vorschriften, München 1823, $\mathbb{4} 413$.

70 Georg Ferdinand Döllinger, Sammlung der im Gebiete der inneren Staats-Verwaltung des Königreichs Bayern bestehenden Verordnungen: Aus amtlichen Quellen geschöpft und systematisch geordnet. Staatsdienst, Dienstesordnung und Gerichtspolizei, dann Geschäftsgang enthaltend, Bd. 17, Abt. XVIII, Abschn. VI., München 1838, \$ 1332 Die eidliche Zusage der Nichttheilnahme an den vom Staate nicht gebilligten Gesellschaften betreffend vom 20. Juli 1832, S. 1058; Amts-Handbuch für die protestantischen Geistlichen des Königreiches Bayern: Enthaltend Verordnungen aus den Jahren 1833-1838 nebst einigen Nachträgen, Bd. 2, Ausgabe 1, Sulzbach 1838, S. 52 f. Hier wird jeweils das genaue Procedere aufgeführt. 
planmäßigen Abschottung der staatlichen, militärischen und kirchlichen Sphäre gegen Infiltrierungsversuche der Illuminaten und anderer Geheimgesellschaften. Er sollte die Loyalität und politische Zuverlässigkeit jedes einzelnen Funktionsträgers gegenüber dem Landesherrn gewährleisten.

Der bayerische Illuminateneid von 1790 hatte den Eid auf das tridentinische Glaubensbekenntnis, den Herzog Albrecht V. erstmals 1568 allen Professoren und Beamten zur Pflicht gemacht hatte und mit dem die ausschließliche Katholizität der Professoren- und Beamtenschaft seit der Gegenreformation gewährleistet worden war, als Vorbild ${ }^{71}$. Er war der Erste seiner Art im Reich, doch wurden bald darauf ähnliche Bestimmungen in anderen Reichsteilen erlassen ${ }^{72}$, während es in Preußen im Militär beim Fahneneid blieb. Zum Beispiel verlangte Österreich, das 1795 alle Geheimgesellschaften verboten hatte, seit 1801 von allen Staatsdienern und Offizieren den Eid, kein Mitglied einer Geheimgesellschaft zu $\operatorname{sein}^{73}$. Und auch die kurpfälzischen Beamten mussten den Illuminateneid ablegen und versichern, ganz allgemein keiner Geheimgesellschaft anzugehören ${ }^{74}$.

In Bayern war die abschreckende Wirkung des Illuminateneides von 1790 mit seinem aufwändigen Verfahren groß. Jeder Offizier, Beamte oder Geistliche wird sich angesichts der angedrohten Folgen genau überlegt haben, ob er einer geheimen Organisation beitreten wollte. Hinzu kam, dass in Bayern nach dem Ende des Illuminatenordens und angesichts der schwachen jakobinischen Präsenz ohnehin fast nur ein Eintritt in Freimaurerlogen außerhalb Bayerns in Betracht kam. Nach 1787 lässt sich allerdings nur eine verschwindend geringe Zahl bayerischer Untertanen in auswärtigen Logen nachweisen ${ }^{75}$.

\section{Die Verordnung gegen geheime Gesellschaften im Neuen Bayern unter Maximilian IV. (I.) Joseph und Montgelas (1799-1825)}

1799 starb Karl Theodor und sein Nachfolger Kurfürst Maximilian IV. Joseph, der als junger Offizier selbst einer Freimaurerloge angehört hatte, hatte neben zahlreichen aufklärerisch gesinnten Beratern und Mitarbeitern auch Maximi-

71 Schaich, Staat und Öffentlichkeit (wie Anm. 9), S. 352.

72 Vgl. die Übersicht bei Härter, Reichstag (wie Anm. 61), S. 375, die nach Schaich allerdings lückenhaft ist. Schaich, Staat und Öffentlichkeit (wie Anm. 9), S. 352.

73 Vgl. zum Eid und zu den Revers, die von Offizieren auszustellen waren, Handbuch aller seit dem Militärjahre 1767, als dem Anfange des in der K. K. österreichischen Armee itzt bestehenden Militär-Oekonomie-Systems, bis zum Schluße des bürgerlichen Jahres 1821, erflossenen und noch als Gesetz bestehenden Normal-Vorschriften, Bd. 3, Prag 1822, S. 18-20. Vgl. daneben Helmut Reinalter, Aufgeklärter Absolutismus und Revolution. Zur Geschichte des Jakobinertums und der frühdemokratischen Bestrebungen in der Habsburgermonarchie, Wien u. a. 1980, S. 216 f.; Härter, Reichstag (wie Anm. 61), S. 375.

74 Winfried Dotzauer, Die Illuminaten im Rheingebiet. In: Der Illuminatenorden (1776-1785/87). Ein politischer Geheimbund der Aufklärungszeit. Hrsg. von Helmut Reinalter, Frankfurt a.M. 1997, S. 125-168, hier S. 155.

75 Schaich, Staat und Öffentlichkeit (wie Anm. 9), S. 369 f. 
lian von Montgelas, der einst als Illuminat aus Bayern hatte fliehen müssen, in seinem Gefolge. Ihn machte er zum Staatsminister. Beide arbeiteten gemeinsam konsequent daran, Bayern in einen modernen, aufgeklärten Staat zu verwandeln ${ }^{76}$. Regierungsvertreter der gegenaufklärerischen Fraktion bekamen ihre Entlassungsurkunde, und Aufklärer, die unter Karl Theodor ins Exil gezwungen worden waren, erhielten die Erlaubnis zur Rückkehr nach Bayern. Manche wurden direkt eingeladen, anderen wurden nach Wartezeiten und Gesuchen zur Wiederanstellung erneut bayerische Ämter zugeteilt. Eine Ausnahme stellte allerdings der Gründer des Illuminatenordens Adam Weishaupt dar ${ }^{77}$, dem Max Joseph trotz der Sympathien, die er für ihn hegte ${ }^{78}$, die Rückkehr nach Bayern nicht gestattete ${ }^{79}$.

Auch erneuerte Max Joseph das Verbot geheimer Gesellschaften und erließ entsprechende Edikte in den Jahren 1799, 1804, 1807 und 1814 ${ }^{80}$. Die Bestimmungen blieben gegenüber den Erlassen Karl Theodors weitgehend unverändert. So wurden abermals alle geheimen Gesellschaften in Bayern verboten. Der Illuminateneid von 1790 wurde 1799 durch die allgemeinere Formulierung ersetzt, dass der Betreffende »in keiner geheimen Gesellschaft, oder Verbindungen, von welchem Namen, oder Art sie auch seyn mögen «, sei ${ }^{81}$. Neben dem Eid wurde nach wie vor ein schriftlicher Revers verlangt und bei Zuwiderhandlungen blieben die Sanktionen in Kraft. Lediglich wurde die Verpflichtung, dass der Eid nach dem Zugang bei jeder Beförderung oder Versetzung zu wiederholen sei, abgeschafft.

Trotz dieser wesentlichen Kontinuitäten in der Praxis änderte sich die Argumentationslinie gegenüber den Edikten Karl Theodors deutlich. Dies zeigt

76 Bayern hatte am Ende der Ära von Montgelas eine modernere staatliche Organisation als die beiden deutschen Großmächte. Auch hatte es dreißig Jahre früher eine Verfassung. Die Prozesse der Bauernbefreiung und der Einführung der Gewerbefreiheit verliefen hingegen langsamer als in Preußen. Vgl. hierzu ausführlich Eberhard Weis, Montgelas, Bd. 1: Zwischen Revolution und Reformation 1759-1799, ergänzte Sonderausgabe, München 2008; Bd. 2: Der Architekt des modernen bayerischen Staates 1799-1838, München 2005.

77 Weishaupt hatte die Hoffnung gehabt, unter dem Ministerium Montgelas nach Bayern zurückzukehren und möglicherweise hier eine gestaltende Rolle einnehmen zu können. Doch wies Montgelas diese Hoffnung 1799 in einem Brief unmissverständlich zurück. Nach Hammermayer befürchtete Montgelas, dass eine Rückberufung Weishaupts Bayerns Ansehen schädigen und Unruhe stiften würde. Hammermayer, Illuminaten in Bayern (wie Anm. 19), S. 156. Vgl. daneben Weis, Montgelas, Bd. 1 (wie Anm. 76), S. 80; Schaich, Staat und Öffentlichkeit (wie Anm. 9), S. 463.

78 Auch protegierte Max Joseph alle Söhne Adam Weishaupts, finanzierte ihnen ein Studium und versorgte sie mit bayerischen Offiziers- und Beamtenstellen. Hierl-Deronco, Norbert, Mit ganz sonderbarem Ruhm und Eyfer. Lebensläufe bayerischer Soldaten 1700-1918, München 1984, S. 60.

79 Doch ernannte Montgelas Weishaupt im Jahre 1808 zum korrespondierenden Mitglied der bayerischen Akademie der Wissenschaften. Engel, Illuminatenorden (wie Anm. 9), S. 386, 398 f.; Weis, Montgelas, Bd. 1 (wie Anm. 76), S. 80.

so Allerdings wurden die Lesegesellschaften, die im Zuge der Illuminatenverfolgung 1786 verboten waren worden, 1802 wieder zugelassen. Uwe Puschner, Verzögerte Aufklärung. Lesegesellschaften in Kurbayern. In: Aufklärung 5 (1990) 2, S. 29-48.

81 HSTA-KA A XIII 2, Bd. 1 Justiz und Polizei: Geheime Gesellschaften, 1751-1816, Die Ablegung des Eides gegen geheime Verbindungen betr., 9. August 1799. 
das ausführliche Edikt gegen geheime Gesellschaften vom 4. November 1799, von dem die Verordnungen aus dem 19. Jahrhundert lediglich Wiederholungen darstellten. Die Anordnung vom 13. September $1814^{82}$ bestand dann gleichbleibend bis zum Ende der Armee 1918 ${ }^{83}$. Hinzu kamen noch verschiedene Ausdifferenzierungen über die Eidleistung in den 1820er Jahren ${ }^{84}$.

Anders als bei den Erlassen Karl Theodors wurde im Edikt vom 4. November 1799 kein durchgehend negatives Bild von Geheimgesellschaften gezeichnet und positive Absichten durchaus anerkannt. Doch wurde der Überzeugung Ausdruck verliehen, »daß geheime Gesellschaften, sie mögen in ihrem Ursprunge, und in ibren Absichten noch so rein seyn, leicht zum Schaden des gemeinen Wesens ausarten ${ }^{85}$, da die Staatsbürger »vom allgemeinen auf besondere Verbältnisse" abgeführt würden. Zudem bestünde die Gefahr, dass die Mitglieder geheimer Gesellschaften zur Befriedigung des Ehrgeizes und der »Leidenschaften unbekannter, oft nichtswürdiger Obern " missbraucht würden ${ }^{86}$ und der Keim der Tugend junger Menschen erstickt oder nur so weit ausgebildet würde, wie es dem Privatnutzen der geheimen Gesellschaft entspreche. »Aus eben dieser Ueberzengung, daß die geheimen Verbindungen, und Gesellschaften sich mit der in jedem wohleingerichteten Staate von der obersten Gewalt unzertrennlichen Oberaufsicht auf die Sitten, Ausbildung, Rube, und öffentliche Sicherheit nicht wohl vereinbaren lassen, ist schon im Jahre 1793 von der deutschen Reichsversammlung der gemeinsame Schlu $\beta$ zu deren allgemeinen Verboth besonders auf öffentlichen Akademien veranlaßt worden. $\ll^{87}$

Die Gefährdung der Religion spielte anders als in den Edikten Karl Theodors nun keine Rolle mehr. Stattdessen wurde rein weltlich und moralisch argumentiert. Von zentraler Bedeutung war das Staatsverständnis, dass keine für die staatliche Oberaufsicht unzugänglichen Bereiche existieren dürften. Die Neuausrichtung in der Begründung des Verbots wird auch daraus ersichtlich, dass keine Kontinuitätslinie zu den Verboten Karl Theodors aufgestellt wurde, sondern auf das Gutachten des Regensburger Reichstags über geheime Gesellschaften aus dem Jahre 1793 Bezug genommen wurde ${ }^{88}$.

82 Allgemeine Verordnung vom 13. September 1814, Erneuerung des Verbots geheimer Gesellschaften und Verbindungen betr., Königlich-Baierisches Regierungsblatt, Nr. 59, München 1814, Sp. 1521-1524.

83 Bezzel, Geschichte des Königlich Bayerischen Heeres 1806-1825 (wie Anm. 32), S. 128; Frauenholz, Geschichte (wie Anm. 3), S. 61 u. 587.

${ }^{84}$ HSTA-KA V 5/1, Kriegsministerialreskripte vom 29.10.1823, 13.3.1824, 14.2.1825 und 25.1.1828.

85 HSTA-KA A XIII 2, Bd. 1 Justiz und Polizei: Geheime Gesellschaften, 1751-1816, Verordnung gegen die geheimen Gesellschaften, 1799.

86 Dies war ohne Zweifel auf Adam Weishaupt gemünzt. Weis, Montgelas, Bd. 1 (wie Anm. 76), S. 79.

87 HSTA-KA A XIII 2, Bd. 1 Justiz und Polizei: Geheime Gesellschaften, 1751-1816, Verordnung gegen die geheimen Gesellschaften, 1799.

881793 hatte sich der Reichstag in Regensburg mit einem Verbot aller geheimen Gesellschaften befasst. Hier fand der Illuminatenorden nur marginal Erwähnung, vielmehr standen die studentischen geheimen Verbindungen im Fokus. Da Österreich die Maximalforderung aufstellte, alle Geheimbünde zu verbieten, obwohl der brandenburgisch-preußische König Friedrich Wilhelm II. Mitglied bei den Rosenkreuzern war, kam es zu keinem Verbot, sondern lediglich zu einem Reichsgutachten, das auf die studentischen Orden beschränkt blieb. Allerdings sahen sich die 
Eine Neuerung während der Regierungszeit Max Josephs war zudem, dass in den seit 1805 neu hinzukommenden Landesteilen die bestehenden Freimaurerlogen nicht verboten wurden, während im altbayerischen Raum die Existenz und das Wirken von Logen untersagt blieben. Doch hatten die Maurer in den neubayerischen Gebieten genaue Bestimmungen zu beachten. Sie wurden strikt observiert, mussten alle drei Monate ihre Mitgliederverzeichnisse bei den Behörden einreichen, und es war ihnen verboten, Beamte, Geistliche oder Offiziere aufzunehmen ${ }^{89}$.

1808 legte Freiherr von Montgelas die Gründe für das Mitgliedsverbot für staatliche Funktionsträger dar. Auf Befehl König Max Josephs richtete er ein Schreiben an den General-Landeskommissär Graf von Thörnheim die »Freimaurer Logen und die Theilnabme der königl. Staatsdiener an ibren Verhandlungen betr. ${ }^{90}$ Hierin wurden die positiven Seiten der Freimaurerei anerkannt, ihre »woblthätige Tendenz «, ihr »Bestreben zur Beförderung alles Guten « und der »Nutzen «, der »in mancherlei Beziehungen « durch sie entstanden sei. Doch wurde keine "absolute[n] Nothwendigkeit ibrer Existenz « gesehen, da ja sowieso jeder Bürger angehalten sei, Gutes zu tun. Entsprechend dieser ambivalenten Haltung fuhr er fort, dass er die bestehenden Freimaurerlogen nicht verbiete, aber für Staatsdiener eine Mitgliedschaft untersage, da die Dienstverpflichtung keine anderen Verbindlichkeiten zulasse ${ }^{91}$. Am 15. Januar 1815 erließ Max Joseph schließlich eine »allerhöchste Verordnung «, in der er die Freimaurerei für alle »in unseren mittel- oder unmittelbaren Staatsdiensten stehenden Individuen « ausdrücklich verbot ${ }^{92}$.

Die vielen Erlasse Max Josephs gegen geheime Gesellschaften, obwohl der Illuminatenorden schon zerschlagen war, erklären sich mit der allgemeinen Revolutionsfurcht, die in Europa seit der Französischen Revolution grassierte. Daneben spielte sicherlich auch eine große Rolle, dass im Jahre 1800 in Bayern

größeren Reichsstände aufgrund der Verhandlungen des Reichstages darin bestärkt, in ihrem Bereich geheime Vereinigungen zu verbieten. Insgesamt zeigt sich eine Verschärfung der Verbots- und Verfolgungspraxis von geheimen Gesellschaften im Reich. Zu den Verhandlungen im Reichstag siehe Härter, Reichstag (wie Anm. 61), S. 357-377; Weis, Illuminatenorden (wie Anm. 9), S. 104.

89 Hammermayer, Illuminaten in Bayern (wie Anm. 6), S. 40 f., 44. Diese Politik führte dazu, dass sich in Bayern auf die Bevölkerung des Jahres 1870 gerechnet ein sehr viel geringerer Prozentsatz der Bevölkerung als Freimaurer engagierte, als im Vergleich zum protestantischen Norden. Ähnlich geringe Prozentsätze gab es ansonsten nur in Württemberg und Baden, die auch zum Großteil katholisch waren. Erst im Kaiserreich gewannen auch die Logen in Bayern vermehrt Mitglieder. Stefan-Ludwig Hoffmann, Die Politik der Geselligkeit. Freimaurerlogen in der deutschen Bürgergesellschaft 1840-1918, Göttingen 2000, S. 135.

90 HSTA-KA A XIII 2, Bd. 1 Justiz und Polizei: Geheime Gesellschaften, 1751-1816, Die Freimaurer Logen und die Theilnahme der königl. Staatsdiener an ihren Verhandlungen betr., 20. Februar 1808.

91 Die uneingeschränkte Loyalität, die Max Joseph von allen Militär- und Zivilangestellten forderte, drückte sich auch in weiteren Verboten von 1814 aus, in denen ihnen allen untersagt wurde, ohne Genehmigung der Regierung für fremde Zeitschriften zu schreiben, außerbayerische Universitäten zu besuchen und an politischen Versammlungen teilzunehmen. Bezzel, Geschichte des Königlich Bayerischen Heeres 1806-1825 (wie Anm. 32), S. 128.

92 Abgedruckt bei Döllinger, Sammlung (wie Anm. 70), Bd. 13, Abt. 15, München 1839, 536, Die Verhältnisse der bestehenden Freimaurerlogen betr., 15. Januar 1815, S. 725 f. 
eine revolutionäre Geheimgesellschaft versuchte, mit Hilfe von französischem Militär das Königshaus zu stürzen, eine Revolution zu entfachen und Bayern zur Republik nach französischem Vorbild zu machen ${ }^{93}$. Da die französischen Truppen dieser jedoch keine Unterstützung gewährte, blieb es bei Plänen. Bei der Verschwörung von 1800 waren einige bayerische hohe Beamte, aber keine Offiziere oder Militärpersonen beteiligt. Die Armee Bayerns spielte nur insofern eine Rolle, als es explizites Ziel der Verschwörer war, diese zu beeinflussen und auf ihre Seite zu bringen, um die Revolution durchzuführen ${ }^{94}$.

Dass der Eid gegen geheime Gesellschaften unter Max Joseph für die Offiziere beibehalten wurde, während es in Preußen beim Fahneneid blieb, erklärt sich möglicherweise auch daraus, dass die militärischen Führer hier im Gegensatz zu Preußen nur einer geringen Reglementierung in ihrem außerdienstlichen Leben unterworfen wurden. Hieran änderte sich bis zur Pranckhschen Heeresreform von 1868 in Bayern nichts ${ }^{95}$. Die Vorgaben für das dienstliche wie das außerdienstliche Verhalten hatten in Bayern zum großen Teil lediglich den Charakter von Empfehlungen, eine gegenseitige Überwachung der Offiziere wurde nicht befohlen und die militärischen Ehrengerichte dienten vorrangig der Verhinderung von Duellen und weniger der Ahndung von standeswidrigem Verhalten ${ }^{96}$. Vielleicht erschien auch aus diesem Grund eine Zusatzregelung notwendig.

\section{Die Angst Ludwigs I. und Maximilians II. vor einer Unterwanderung der Armee}

Auch unter den Königen Ludwig I. (1825-1848) und Maximilian II. (18481864) war die Angst vor geheimen Vereinigungen im Militär deutlich ausgeprägt und mit der Furcht vor revolutionären Ideen, Verschwörung, Verrat und inneren Umsturzversuchen verwoben. Die Erinnerung an den radikal-aufklä-

93 Unter den mehrere Dutzend umfassenden Verschwörern befand sich abgesehen von dem abgefallenen Joseph von Utzschneider, den die Illuminaten seit 1784 als ihren Erzfeind betrachteten, nur ein einziger Illuminat. Weis, Illuminatenorden (wie Anm. 9), S. 106 f.

94 Maximilian IV. Joseph und Montgelas unterließen es die Verschwörer von 1800 öffentlich zu verfolgen, sondern unterstellten lediglich einige von ihnen polizeilicher Aufsicht. Selbst hohe Beamte, bei denen eine Mitgliedschaft bekannt war, erlitten keine dienstlichen Nachteile, sondern erhielten auch nachfolgend noch hohe Ämter. Weis bewertet die Tatsache, dass Max Joseph und Montgelas auf Strafmaßnahmen verzichteten, wie folgt: »Da sie keine Strafmaßnabmen durchführten, bewahrten Max Joseph und Montgelas den inneren Frieden, schufen keine Märtyrer und wabrten den Ruf des neuen Bayern als eines Landes der Toleranz, sie sicherten dem Staat, der Wirtschaft und der Wissenschaft aber auch weiterbin die Mitarbeit einiger der besten und originellsten Köpfe. «Vgl. hierzu ausführlich Weis, Montgelas, Bd. 2 (wie Anm. 76), S. 60-86, Zitat S. 86.

95 Die allgemeinen Dienstvorschriften der bayerischen Armee von 1823 blieben bis 1868 in Kraft. Dienst-Vorschriften (wie Anm. 69).

96 Gahlen, Offizierskorps (wie Anm. 50), S. 477-558. 
rerischen pseudomaurerischen Illuminatenorden wurde nach wie vor wach gehalten ${ }^{97}$. Hinzu kam, dass die katholische Kirche Geheimgesellschaften und insbesondere die Freimaurerei als religiöse Sekten bekämpfte ${ }^{98}$. Beides bewirkte, dass Ludwig noch als Kronprinz den im Jahre 1819 an ihn herangetragenen Vorschlag abgelehnt hatte, nach dem Vorbild Preußens und Russlands das Protektorat über sämtliche bayerische Logen zu übernehmen ${ }^{99}$. Vielmehr wurde 1843 und 1858 das Verbot der Mitgliedschaft in den Freimaurerlogen für alle Staatsdiener wiederholt und im Hinblick auf die Armee betont, dass es für alle im Heeresdienst (Waffen- und Verwaltungsdienst) angestellten Personen, einschließlich der pensionierten und charakterisierten Individuen, gleich verbindlich und wirksam sei ${ }^{100}$.

Neben dem Misstrauen gegen geheime Gesellschaften wie die Illuminaten und Freimaurer spielten die revolutionären Ereignisse in den Regierungszeiten Ludwigs I. und Maximilians II. für die Sorge der Monarchen um die Zuverlässigkeit der Armee eine Rolle. Bei König Ludwig I. können derartige Bedenken verstärkt seit der Julirevolution in Frankreich 1830 verzeichnet werden. Hiervon zeugt nicht zuletzt sein Signat vom 23. Juli 1831, in dem er bemerkte: »Es ist ein wachsames Auge darauf zu haben, daß alle Inspecitions Officiere, Profeßoren und Lebrer im Cadettencorps von guter Gesinnung seyen, denn leider offenbart sich's, daß - so zuverlässig auch die älteren Officiers sind, gerade jüngere, die noch keinen Feldzug gemacht, von den verderblichen Grundsätzen der nemesten Zeit angesteckt sind «101.

Auch nahm Ludwig I. jeden Verdacht auf Geheimbündelei sehr ernst. Dies zeigt zum Beispiel der Vorfall von 1831, als gegen die späteren Kriegsminister Ludwig von Lüder (1795-1862) und Karl Weishaupt (1787-1853) Untersuchungen veranlasst wurden. ${ }^{102}$ Letzterer war ein Sohn des Begründers des Illuminatenordens Johann Adam Weishaupt. Die beiden Offiziere dienten da-

97 Hammermayer, Illuminaten in Bayern (wie Anm. 6), S. 44. Vgl. auch Lankes, München (wie Anm. 67), S. 550.

98 Agethen, Geheimbund und Utopie, S. 287-293.

99 Hammermayer, Illuminaten in Bayern (wie Anm. 6), S. 44.

100 HSTA-KA Kriegsministerialreskript V 5/1, Nr. 5398: Die Theilnahme der Beamten und öffentlichen Diener an geheimen Gesellschaften und Verbindungen betr., 11.6.1843. Auf das Verbot von 1858 wurde in der Diskussion im Kriegsministerium von 1884 verweisen. HSTA-KA MKr 11530 Geheime Gesellschaften 1814-1920, Freimaurer betreffend, 4.3.1884. Eine charakterisierte Beförderung in einen Offiziersdienstgrad bedeutete, dass der Betreffende nur den Titel, aber nicht die Dienststellung des Offiziersranges innehatte.

101 HSTA-KA A III 17 Signat Ludwig I. vom 23.7.1831. Die liberale Bewegung hatte auch im Offizierskorps und hier insbesondere in den pfälzischen und fränkischen Regimentern Sympathisanten. Für die gesamte Zeit des Vormärz lässt sich feststellen, dass die Mehrzahl der Offiziere wohl monarchisch-konservativ gesinnt war, aber eine Minderheit, gerade im jüngeren Offizierskorps, mit den Ideen des Liberalismus sympathisierte, jenen Ideen also, von denen sich die politische Opposition leiten ließ. Hierzu Jörg Calließ, Militär in der Krise. Die bayerische Armee in der Revolution von 1848/49, Boppard a. Rh. 1976, S. 79 f.; Karl Demeter, Das deutsche Offizierkorps in Gesellschaft und Staat 1650-1945, 4., überarb. u. erw. Aufl., Frankfurt a. M. 1965, S. 160; Wolf D. Gruner, Das Bayerische Heer 1825 bis 1864. Eine kritische Analyse der bewaffneten Macht Bayerns vom Regierungsantritt Ludwigs I. bis zum Vorabend des deutschen Krieges, Boppard a. Rh. 1972, S. 194.

102 Vgl. hierzu Gahlen, Offizierskorps (wie Anm. 50), S. 126. 
mals im Artilleriereferat des Kriegsministeriums. Weishaupt und Lüder diskutierten mit einigen anderen Offizieren des Ministeriums in ihrer Freizeit privat und öffentlich Probleme der Armee. Ludwig I. wurde über "[...] das auffallende Benehmen einiger Artillerie-Offiziere im Wirtshaus ,Zum Birkenstock « informiert und argwöhnte Verrat. Am 14. Dezember 1831 gab er den Befehl: »Wenigstens ein abschreckendes Beyspiel stattfinden zu lassen, scheint mir notbwendig, und dass solches an dem von mir selbst ausgezeichnet wordenen Major Weishaupt $t^{103}$ geschehe. Auch an dem im Kriegsministerium sitzenden Becker dürfte es nicht übel sein, eines zu geben. Die übrigen wären zu versetzen. «104 Die folgende Vermittlung des Kriegsministers von Weinrich verhinderte, dass die Drohungen Ludwigs I. umgesetzt wurden und gegen Weishaupt ein Kriminalverfahren eingeleitet wurde. Er wurde stattdessen in die Gieß- und Bohranstalt Augsburg versetzt. Lüder wurde in die Festung Landau kommandiert ${ }^{105}$. Weder Weishaupt noch Lüder erlitten langfristige Karrierenachteile. Karl Weishaupt stieg wie einer seiner Brüder zum General auf und wurde im Jahre 1848 bayerischer Kriegsminister ${ }^{106}$. Lüder hatte dasselbe Amt zwischen 1849 und 1855 sowie von 1859 bis 1861 inne. ${ }^{107}$

Als Verschwörung der Offiziere der Münchner Garnison, die mit ultramontanen Intriganten gemeinsame Sache gemacht hätten, bewertete Ludwig I. deren Verhalten 1848. ${ }^{108}$ Bei den Unruhen am 10. und 11. Februar dieses Jahres aufgrund der Affäre des Königs mit Lola Montez ${ }^{109}$ verhielten sich die Abteilungen der Linie passiv und bestimmten damit Verlauf und Ausgang der Februarunruhen. Der Kriegsminister Anton von der Mark erklärte dem König am 11. Februar, er könne die Zuverlässigkeit der Armee nicht mehr garantieren ${ }^{110}$. Daraufhin erfüllte Ludwig I. am 11. Februar alle von der Bürgerschaft Mün-

${ }_{103}$ Auch Ludwig I., der als Kronprinz mit Adam Weishaupt korrespondiert hatte, obwohl er sicherlich nicht mit dem Illuminatismus sympathisierte, hatte diese Protegierung, die Karl Weishaupt schon von Max Joseph erfahren hatte, bereitwillig fortgesetzt. Engel, Illuminatenorden (wie Anm. 9), S. 386; Weis, Montgelas, Bd. 1 (wie Anm. 76), S. 80.

104 Zitiert nach Lankes, München (wie Anm. 67), S. 550.

105 Hierl-Deronco, Mit ganz sonderbarem Ruhm (wie Anm. 78), S. 70-76; Lankes, München (wie Anm. 67), S. 550.

106 Engel, Illuminatenorden (wie Anm. 9), S. 386; Weis, Montgelas, Bd. 1 (wie Anm. 76), S. 80.

107 Edgar Graf von Matuschka und Wolfgang Petter, Organisationsgeschichte der Streitkräfte. In: Handbuch zur deutschen Militärgeschichte 1648-1939. Hrsg. vom Militärgeschichtlichen Forschungsamt, Bd. 2, Abschnitt IV: Militärgeschichte im 19. Jahrhundert 1814-1890, Frankfurt a. M. 1979, S. 302-358, hier S. 296-298.

108 Vgl. hierzu Gahlen, Offizierskorps (wie Anm. 50), S. 523-526.

109 Lola Montez (1821-1861), eigentlich Elizabeth Rosanna Gilbert, war eine irische Tänzerin, die seit Oktober 1846 die Geliebte König Ludwigs I. von Bayern war. Lola Montez oder eine Revolution in München. Katalog zur Ausstellung des Münchner Stadtmuseums vom 13. November 1998 bis 31. Januar 1999. Hrsg. von Thomas Weidner und Ulrike Steiner, München 1998; Bruce Seymour, Lola Montez. A life, New Haven 1996.

110 Angesichts der zahlenmäßigen Unzulänglichkeit der Gendarmerie hatte der König seit jeher mit der Landwehr als Ordnungstruppe bei Tumulten gerechnet. Der Landwehroberst von Maffei erklärte jedoch, er wage nicht, seine Truppe ausrücken zu lassen. Aber auch auf das Linienmilitär Münchens war kein Verlass mehr. Es wäre zwar zum persönlichen Schutz des Königs und der Residenz einzusetzen gewesen, aber nicht zum Schutz von Lola Montez. Heinz Gollwitzer, Ludwig I., Königtum im Vormärz. Eine politische Biographie, München 1986, S. 687. 
chens gestellten Forderungen. Er nahm das Schließungsdekret für die Universität zurück, riet Lola Montez, sich aus der Stadt zu entfernen ${ }^{111}$ und notierte erschüttert: "Das Militär versagt den Dienst, da die Soldaten hierzu aufgebetzt werden. Der Verrat ist vollkommen. " ${ }^{112}$ Nach der Abreise von Lola Montez beschädigten Demonstranten deren Villa schwer. Die verantwortlichen Offiziere gaben keinen Befehl zum Einsatz, so dass schließlich der König selbst erschien und eigenhändig die Räumung der Straße durch die Truppen leitete ${ }^{113}$.

Nach seiner Niederlage verlangte er die Verurteilung der verantwortlichen Offiziere, deren Handeln er als Verschwörung gegen sich wertete. Aber seine diesbezüglichen Anweisungen stießen auf den hartnäckigen Widerstand der militärischen Dienststellen. Als der König bei seiner Forderung nach schärfster Bestrafung blieb, verhängten die zuständigen Dienststellen äußerst milde Sanktionen, wie etwa einen Tag Stubenarrest ${ }^{114}$.

Auch in der Folgezeit wurde der Gegensatz zwischen Ludwig I. und dem Offizierskorps nicht entschärft. Das Verhältnis blieb angespannt, und die ständige Sicherung der Villa von Lola Montez wurde nur widerwillig vollzogen. Der König musste die Erfahrung machen, dass ein großer Teil der Offiziere in der Münchner Garnison jetzt grundsätzlich oppositionell eingestellt war. Als er versuchte, die Stimmung durch Versetzung von 30 Beteiligten zu Regimentern anderer Garnisonen zu beeinflussen, wurde er mit dem entschiedenen Widerstand des Kriegsministers Anton von der Mark konfrontiert. Wie bedeutsam dessen Unterstützung in der Armee gewesen sein muss, zeigt die Tatsache, dass Ludwig sich schließlich widerstrebend dazu durchrang, ihn auf seinem Posten zu belassen ${ }^{115}$.

Die Autoritäts- und Vertrauenskrise zwischen dem König und der militärischen Führungsschicht ging so weit, dass diese nicht einmal zur Abwehr der auf eine Umgestaltung des politischen Systems zielenden Bestrebungen bereit war. Als Ludwig I. am 6. März 1848 die Vereidigung der Armee auf die Verfassung proklamierte, fand dies die ausdrückliche Unterstützung vieler Offi-

111 Calließ, Militär in der Krise (wie Anm. 101), S. 94.

112 Vier Tage später machte Ludwig einen Nachtrag zu den Notizen vom 11.2.1848: »Ich schämte mich, als ich die bayerische Uniform zur Tafel anzog. Im berüchtigten Memorandum vor einem Jabr, da des bayerischen Heeres Trene Zweifel erhoben wurde, war's empörende Verleumdung - jetzo, was die Münchener Besatzung betrifft, Wabrheit, daßnicht auf sie zu bauen «. Zit. nach Gollwitzer, Ludwig I. (wie Anm. 110), S. 687.

113 Die Offiziere beriefen sich im Nachhinein auf eine Vorschrift, die für den Waffengebrauch die Aufforderung durch die Polizeibehörde voraussetzte. Allerdings war innerhalb dieser Vorschrift ausdrücklich festgelegt, dass Militär auch ohne eine solche Erlaubnis Waffengewalt einsetzen konnte, wenn die einer Abteilung anvertrauten Personen oder Güter auf andere Weise nicht verteidigt werden konnten. Calließ, Militär in der Krise (wie Anm. 101), S. 93-95.

114 Ebd., S. 94 f.

115 Graf Bernstorff an König Friedrich Wilhelm IV., München 21.2.1848. In: Gesandtschaftsberichte aus München 1814-1848, bearbeitet von Anton Chroust, Abt. 2: Die Berichte der österreichischen Gesandten, Bd. 3: Die Berichte aus der Zeit des Ministeriums Abel bis zur Thronentsagung König Ludwigs I.: von Nov. 1837 bis zum März 1848, S. 385; Freiherr von Brenner an Fürst Metternich, München 27.2.1848. In: Ebd., S. 537; Freiherr von Brenner an Fürst Metternich, München 6.3.1848. In: Ebd., Anm. 1. Vgl. auch Calließ, Militär in der Krise (wie Anm. 101), S. 96. 
ziere, da damit die Verfügungsgewalt des Königs über die Armee eingeschränkt wurde ${ }^{116}$. Die Haltung der Armee war ein wesentliches Motiv für den Thronverzicht Ludwigs I. am 20. März $1848^{117}$.

Auch wenn Ludwig I. das Verhalten der militärischen Führer während der Februarunruhen 1848 als Verschwörung gegen sich wertete, muss festgehalten werden, dass hier kein geheimes militärisches Netzwerk am Werk war. Die Offiziere der Münchener Garnison agierten vielmehr als Teil der kirchlichkonservativen und ständisch-konservativen Oberschicht, die zuvor die Stütze des monarchischen Prinzips dargestellt hatte, nun aber durch das kontinuierliche ehrgeizige Streben von Lola Montez nach gesellschaftlicher Anerkennung und politischem Einfluss in immer entschiedenere Opposition ging. Die Offiziere waren dabei die Gruppe, die am längsten zum König gestanden hatte, aber deren Loyalitätsverhältnis zur Krone aufgrund der Provokationsaktionen des Monarchen und seiner Geliebten seit 1847 kontinuierlich zerrüttet worden war $^{118}$. Auch vor den Februarunruhen hatten die Offiziere immer wieder offen gegenüber Ludwig I. ihr Missfallen über die Zustände an der Staatsspitze ausgedrückt, sodass von konspirativem Verhalten hier nicht die Rede sein kann. Fehlende Loyalität, Opposition und damit auch Verrat aufgrund des Verstoßes gegen die Gehorsamspflicht waren aber aus Sicht des Königs berechtigte Vorwürfe.

Nach dem Erfolg der bürgerlich-liberalen Revolution und dem Wechsel an der obersten Staatsspitze stellten sich das Offizierskorps wie auch die Armee insgesamt loyal in den Dienst des neuen Königs und der neuen, nun mit liberalen Ministern besetzten Regierung ${ }^{119}$. Die radikalen demokratischen Bewegungen während der Revolutionsjahre hatten eine deutliche Vereinheitlichung der politischen Strömungen im Offizierskorps und eine klare monarchischkonservative Positionierung bewirkt. Die militärischen Truppenführer führten die Einsätze gegen Aufstände und offene Unruhen demokratisch-republikanischer Anhänger im Jahre 1848 generell zuverlässig aus ${ }^{120}$.

Obwohl seit dem Thronverzicht Ludwigs I. wieder ein hundertprozentiges Loyalitätsverhältnis zur Dynastie herrschte, wurde das Verhältnis Maximilians II. zum Offizierskorps durch seine Angst vor unzuverlässigen Tendenzen in der Armee wesentlich geprägt. ${ }^{121}$ Er blieb dem Militär gegenüber misstrauisch,

116 Calließ, Militär in der Krise (wie Anm. 101), S. 195, 200.

117 Christian Lankes, Bürgerliche Revolution und militärische Reaktion. München und seine Garnison zur Zeit König Maximilians II. In: Stadt und Militär 1815-1914. Wirtschaftliche Impulse, infrastrukturelle Beziehungen, sicherheitspolitische Aspekte. Hrsg. von Bernhard Sicken, Paderborn 1998, S. 337-357, hier S. 343.

118 Calließ, Militär in der Krise (wie Anm. 101), S. 84 f., 88.

119 Ebd., S. 201.

120 In den überlieferten Akten finden sich nur wenige Hinweise auf Offiziere, die mit der revolutionären Bewegung sympathisierten. Insgesamt enthält das von Jörg Calließ durchgearbeitete Material 32 diesbezügliche Hinweise. Beim Aufstand in der Pfalz desertierten vier bayerische Leutnants. Wurde aber von Offizieren mit demokratischen Neigungen berichtet, so fügten die Kommandostellen zumeist ausdrücklich hinzu, dass die übrigen Mitglieder des Offizierskorps diese Überzeugungen nicht teilen würden. Ebd., S. 121, 145, 160; Sabrina Müller, Soldaten in der deutschen Revolution von 1848/49, Paderborn u. a. 1999, S. 176.

121 Vgl. hierzu Gahlen, Offizierskorps (wie Anm. 50), S. 528 f. 
befürchtete die Unterwanderung der Truppe durch die "wühlende Parthey«, welche die Soldaten zum Aufruhr verleite, und ließ sich bis über das Jahr 1855 hinaus regelmäßig Berichte über den »Geist im Heer "vorlegen. Noch am 3. November 1858 holte er bei Kriegsminister Wilhelm Ritter von Manz streng vertraulich Erkundungen darüber ein, »wie sich nunmehr die politischen $\mathrm{Ge}$ sinnungen derjenigen Offiziere gestaltet haben, die [...] in den Bewegungsjabren 1848/49 eine gewisse Unsicherheit in ibrer politischen Haltung an den Tag gelegt « hatten ${ }^{122}$. Der Kriegsminister berichtete, dass die Mehrzahl der in den Jahren 1848/49 »anrüchigen Individuen " inzwischen durch Entlassung aus dem Heere geschieden sei. Die übrigen - namentlich wurden Max Graf von Bothmer ${ }^{123}$, Max Aldosser, Joseph Feichtmayer, Carl Schultze und Ferdinand Kohlermann angeführt - hätten aber inzwischen ihre Zuverlässigkeit bewiesen, so dass sie sämtlich befördert worden seien. Sie hätten ihre damaligen Gesinnungen geändert, »welche großenteils nur aus jugendlicher Unüberlegtheit in damaliger ganz anders als gegenwärtig gestalteten Zeitperiode hervorgegangen waren." Dem ganzen Offizierskorps wurde vom Kriegsministerium die " $Z u$ verlässigkeit« im monarchischen Sinne bescheinigt ${ }^{124}$.

\section{Versuche der Öffnung der Freimaurerei für die bayerische Armee im Kaiserreich}

Auch im Kaiserreich musste jeder bayerische Offizier den Eid schwören, dass er keiner geheimen Gesellschaft und keinem dem Staat nicht angezeigten Verein angehörte. Im Gegensatz zu Preußen, wo zwischen den Freimaurerlogen und dem Königshaus enge Beziehungen existierten, wurden in Bayern die Freimaurer nach wie vor unter dieses Verbot gefasst. Es ist kein Vorfall überliefert, dass sich ein Offizier diesem Eid zuwider verhalten hätte. Auch wurde in der Zeit des Kaiserreichs kein Einziger in einer "nichtstaatserhaltenden« politischen Richtung tätig ${ }^{125}$.

Hier spielte sicherlich eine Rolle, dass nach der für Bayern verheerenden Niederlage im Feldzug von 1866, in der die Kriegsuntüchtigkeit der bayerischen Armee offen zutage getreten war, 1868 eine umfassende Heeresreform nach preußischem Muster unter der Leitung des Kriegsministers Generalmajor

122 HSTA-KA A III 17, Unterakt 25; vgl. auch Rainer Braun, Der König und seine Armee. In: König Maximilian II. von Bayern 1848-1864, hrsg. vom Haus der bayerischen Geschichte, Rosenheim 1988, S. 163-172, hier S. 171.

123 Der seiner Zeit wegen liberaler Ansichten suspekte Hauptmann Graf Bothmer stieg zum Chef des bayerischen Generalstabs auf. Demeter, Das deutsche Offizierkorps (wie Anm. 101), S. 160.

124 HSTA-KA A III 17 Schreiben des Kriegsministers von Manz an Ludwig I. vom 5.11.1858, Die politischen Gesinnungen einiger Offiziere betr.; ediert bei Demeter, Das deutsche Offizierkorps (wie Anm. 101), Anlage 19: Brief des Kriegsministers an den König, S. 309 f.

125 Hermann Rumschöttel, Das bayerische Offizierkorps 1866-1914, Berlin 1973, S. 226-228. 
Sigmund Freiherr von Pranckh durchgeführt worden war ${ }^{126}$. Mit der Reform wurde auch die preußische Auffassung übernommen, den Kastengeist nicht mehr als negativ anzusehen und eine geistige Homogenität des Offizierskorps anzustreben. Ein politisches Desinteresse wurde gezielt gefördert, um die militärischen Führer in ihrer monarchischen Gesinnung nicht zu gefährden. Für staats- oder militärfeindliche, sozialdemokratische oder sanarchistische< Zeitungen bestand ein generelles Lektüreverbot. Daneben war jeder Regimentskommandeur berechtigt, seinen Offizieren das Lesen einer bestimmten Zeitung zu untersagen. Zudem wurden gesellige Kontakte mit der Zivilbevölkerung als Dienst verstanden und genauestens geregelt und überwacht ${ }^{127}$.

Ende 1883 und Anfang 1884 wurde in Bayern ein Versuch durch einen Landtagsabgeordneten, der als Logenvertreter fungierte, unternommen, die Freimaurerei für Offiziere zu öffnen. Er plädierte dafür, dass es sich bei den Freimaurern um keine geheime und keine politische Gesellschaft handelte und daher das Verbot aufgehoben werden solle. Obwohl die Freimaurerlogen seit 1808 wieder erlaubt seien, sei trotzdem den Staatsdienern und Militärangehörigen bis in die Gegenwart die Mitgliedschaft in den Freimaurerlogen verboten. Er führte insbesondere die Bestimmung des Reichsmilitärgesetzes von 1874, dass allen zum aktiven Heer gehörenden Militärpersonen lediglich die Teilnahme an politischen Vereinen und Versammlungen untersagt sei, die Freimaurer aber keine politische und keine geheime Vereinigung seien, als Argument dafür an, dass die bayerische Regelung nicht mit den heutigen Gesetzen vereinbar sei. Zur Stützung seiner Argumentation betonte er schließlich noch, dass die Freimaurerlogen durch das Kaiserhaus besonders protegiert würden. Der bayerische Kriegsminister ließ daraufhin einen Rechercheauftrag ausgeben, ob die Offiziere in Preußen Mitglieder im Freimaurerorden sein durften und was für Regelungen hier griffen ${ }^{128}$.

Diesbezüglich berichtete der Königlich Bayerische Militär-Bevollmächtigte in Berlin am 23.12.1883, dass in Preußen die Freimaurerei für Offiziere nie verboten gewesen sei und Angehörige des Königshauses Mitglieder seien. In Preußen würden die Freimaurer als kein politischer Verein angesehen. Der Militär-Bevollmächtigte ging auch auf die Situation in Württemberg und Sachsen ein. Württembergischen Offizieren sei die Freimaurerei erlaubt, aber nur wenige von ihnen seien Mitglieder in den Logen. In Sachsen sei den Offizieren diese seit 1852 verboten. Hier vermutete der Militär-Bevollmächtigte als Grund das politische Agieren der Freimaurer »zu Zeiten innerer politischer Kämpfe«, wobei er auf die Revolutionsjahre anspielte ${ }^{129}$.

126 Rumschöttel betont, dass im Gegensatz zur Geschichte des preußischen Offizierskorps die entscheidende Zäsur nicht in der Zeit nach 1814 oder um 1848/49, sondern in den Jahren 18661870 liegt. Ebd., S. 286.

127 Ebd., S. 211, $227 \mathrm{f}$.

128 HSTA-KA MKr 11530 Geheime Gesellschaften 1814-1920, Die Freimaurer betreffend, 13.12.1883.

129 HSTA-KA MKr 11530 Geheime Gesellschaften 1814-1920, Die Freimauer vom K.B. MilitärBevollmächtigen in Berlin betreffend, 23.12.1883. 
Die sich im März und April 1884 anschließende Diskussion im Kriegsministerium bezüglich des Antrags, die Freimaurerei für die bayerischen Offiziere zuzulassen, war anfangs sehr wohlwollend. Es zeigte sich eine starke Orientierung an Preußen. Aus dem dortigen Umgang mit den Freimaurern sei offensichtlich, dass diese nicht staatsgefährdend seien. Überhaupt sei es fragwürdig, ob ein Eid gegen geheime Gesellschaften notwendig sei. Schließlich genüge in Preußen der Fahneneid, der die Offiziere zur »Trene gegen den Monarchen « und zur »Förderung dessen Wobl« verpflichte, dass die Offiziere nicht in unerlaubte Vereine eintreten würden. Allerdings wurde diesbezüglich $\mathrm{zu}$ bedenken gegeben, dass die zivilen Staatsdiener den Eid gegen geheime Gesellschaften schwören müssten und eine Abschaffung allein für die Offiziere ungünstig sei. Zumindest sei es angezeigt, hierfür einen geeigneteren Zeitpunkt abzuwarten. ${ }^{130}$

Die positive Haltung unter den Referenten im Kriegsministerium änderte sich 1884 auf Grund eines äußeren Faktors, durch die päpstliche Enzyklika vom 20. April diesen Jahres, welche die Freimaurerei als unvereinbar mit der katholischen Konfession bezeichnete. Hinzu kam, dass zur Enzyklika noch ein Hirtenbrief des Münchner Erzbischofs erschien, welcher deren Argumentation aufnahm. Nun wurde im Kriegsministerium angemahnt, dass die Aufhebung des Verbots des Beitritts von Offizieren im Freimaurerorden erhöhte Tragweite haben könnte. Entsprechend wurde angezweifelt, ob der Zeitpunkt für die Aufhebung des Verbots im Moment günstig sei. Der Kriegsminister äußerte offen, dass er die kirchliche Anschauung über die Freimaurerei nicht teile, aber auch wie die anderen im Kriegsministerium befürchte, dass eine Aufhebung des Verbots als direkte Entgegenstellung gegen geistliche Weisungen gewertet und öffentliches Missfallen erregen würde. Aufgrund dieser Argumente wurde im Kriegsministerium beschlossen, dass der Vorgang vorerst zu den Akten zu legen sei. Falls ein besserer Zeitpunkt komme, solle das Anliegen neu aufgerollt werden. Es wurde vorgeschlagen, in diesem Fall zuerst die Angelegenheit im Ministerrat zu besprechen. ${ }^{131}$

Die Diskussion im Kriegsministerium macht deutlich, dass 1883 keine Furcht vor geheimen Gesellschaften und einer Unterwanderung des Staates durch diese mehr bestand. Insgesamt lagen die Sympathien eindeutig beim preußischen Umgang mit der Freimaurerei. Dass trotzdem die Pläne zur Neuerung der Verordnung gestoppt wurden, lag am Erscheinen der päpstlichen Enzyklika. Auch wenn aus dem Schriftwechsel im Kriegsministerium hervorgeht, dass hier der päpstlichen Verdammung der Freimaurerei nicht zugestimmt wurde, zeigt sich eine starke Rücksichtnahme des bayerischen Kriegsministeriums auf die öffentliche Meinung und den sozialen und religiösen Frieden in Bayern. In der bayerischen Öffentlichkeit spielte die katholische Kirche eine nicht zu unterschätzende Rolle, auch wenn seit den Reformen unter Montgelas die strikte Trennung von Kirche und Staat durchgesetzt wor-

130 HSTA-KA MKr 11530 Geheime Gesellschaften 1814-1920, Freimaurer betreffend, 4.3.1884.

131 HSTA-KA MKr 11530 Geheime Gesellschaften 1814-1920, Freimaurer betreffend, 1884-1885. 
den war ${ }^{132}$. Nachdem 1738 und 1751 die ersten päpstlichen Bullen gegen die Freimaurerei erlassen wurden, erschienen zwischen 1814 und 1902 weitere 18 päpstliche Bullen, Enzykliken und apostolische Schreiben, die sich gegen Geheimbünde und die Freimaurer wandten und beide als unvereinbar mit der katholischen Religion anprangerten. Insbesondere seit den 1860er Jahren traten zehn dieser päpstlichen Rechtsakte und Verlautbarungen in Erscheinung ${ }^{133}$. Die Rücksichtnahme auf die öffentliche Meinung, wie sie sich hier in den Akten des Kriegsministeriums zeigt, war ein Charakteristikum des Herrschaftssystems im Königreich Bayern. Dieses zielte auf eine Begrenzung der sozialen Gegensätze und Spannungen sowie eine innere Zustimmung der Regierten, was nicht zuletzt auch daran lag, dass eine effiziente Kontrolle der Bevölkerung durch militärische oder polizeiliche Maßnahmen sehr viel mehr gekostet hätte, als der bayerische Staat finanzieren konnte ${ }^{134}$.

Erst im Jahre $1908 \mathrm{kam}$ die Angelegenheit im bayerischen Kriegsministerium erneut zur Sprache ${ }^{135}$. Damals war ein neues reichsweites Vereinsgesetz erlassen worden, worauf das Verbot des Freimaurerordens für sächsische Offiziere aufgehoben worden war. Im Kriegsministerium wurde deswegen diskutiert, ob auch hier im Lande Konsequenzen zu ziehen seien und das Ministerium einen Vorschlag zur Öffnung der Freimaurerei für Offiziere erarbeiten solle. Befürworter führten an, dass zwar keine zwingende Veranlassung bestünde, aber die liberale Fraktion in der Abgeordnetenkammer in nächster Zeit hierauf eingehen könnte. Es sei weit zweckmäßiger, wenn das Kriegsministerium von sich aus das Verbot aufhöbe, als wenn es dies auf Drängen der liberalen Partei machen müsste. Gegenstimmen, welche die Bestimmung aufrechterhalten wollten, finden sich in dem überlieferten Diskurs nicht. Vielmehr herrschte allgemein die Ansicht, dass das Verbot nach der jetzigen Gesetzeslage nicht gerechtfertigt sei, da die Freimaurer weder unter die geheimen noch unter die politischen Gesellschaften fielen. Trotzdem entschied sich das Kriegsministerium letztendlich dazu, keine Initiative zu ergreifen, sondern abzuwarten, bis ein äußerer Anlass käme.

Dies war bis zum Ende der bayerischen Armee nicht mehr der Fall. In der Akte des Kriegsministeriums über Geheime Gesellschaften findet sich nachfolgend noch ein Vermerk vom 26. Februar 1912 ${ }^{136}$, dass die Akte unentschie-

132 Heinz Hürten, Die katholische Kirche seit 1800. In: Handbuch der bayerischen Geschichte, Bd. 4: Das Neue Bayern. Von 1800 bis zur Gegenwart, Teilbd. 2: Die innere und kulturelle Entwicklung. Hrsg. v. Alois Schmid, 2. Aufl., München 2007, S. 300-330, hier S. 300-318.

133 Vgl. hierzu Harald Schrefler, Der Papst und die Freimaurer. Ein wissenschaftlicher Diskurs, Innsbruck 2010, S. 70-79.

134 Marita Krauss, Herrschaftspraxis in Bayern und Preußen im 19. Jahrhundert. Ein historischer Vergleich, Frankfurt a. M. 1997, S. 387; Eberhard Weis, Das neue Bayern - Max I. Joseph, Montgelas und die Entstehung und Ausgestaltung des Königreichs 1799 bis 1825. In: Wittelsbach und Bayern. Hrsg. von Hubert Glaser, Bd. III.1: Krone und Verfassung. König Max I. Joseph und der neue Staat, München 1980, S. 49-64, hier: S. 61 f.; vgl. auch zur Wirkungsmächtigkeit der Angst vor dem Urteil der Öffentlichkeit bei militärischen Entscheidungen Gahlen, Offizierskorps (wie Anm. 50), bes. S. 177; Rumschöttel, Offizierkorps (wie Anm. 119), S. 83 f.

135 HSTA-KA MKr 11530 Geheime Gesellschaften 1814-1920, Kriegsministerialprotokoll: Aufhebung des Verbotes des Freimaurer-Ordens für die Sächsischen Offiziere, 31.5.1908.

136 HSTA-KA MKr 11530 Geheime Gesellschaften 1814-1920, Eintrag vom 26.2.1912. 
den zu diesem Zeitpunkt an den Abteilungschef Köberle der Armee-Abteilung I im Bayerischen Kriegsministerium übergeben worden sei. Sie endet dann am 16. November 1918 mit folgendem Eintrag: "Die Frage, ob für die Offiziere u.s.w. das Verbot der Teilnabme am Freimaurer-Orden noch weiterhin aufrecht erbalten werden soll, bedarf mit Rücksicht auf die Nenordnung der Verbältnisse keiner Erörterung mebr. «137 Am 12./13. November 1918 hatte Ludwig III. mit der »Anifer Erklärung « einen Tag nach der Ausrufung des Freistaats Bayern die bayerischen Beamten und Soldaten von ihrem Treueid entbunden ${ }^{138}$.

\section{Zusammenfassung}

Im Bund der Illuminaten waren bayerische Offiziere zu einem hohen Prozentsatz vertreten. Dennoch hatte keiner von ihnen eine zentrale Stellung in der Geheimgesellschaft. Sobald das kurfürstliche Verbot der Illuminaten erlassen wurde, fügten sich die Offiziere widerstandslos, traten aus dem Orden aus und leisteten den Eid gegen geheime Gesellschaften. Im gesamten 19. Jahrhundert übte mit der Ausnahme der Vertrauenskrise 1848 im Zuge der Februar- und Märzunruhen das Offizierskorps seinen Dienst loyal aus.

Dass trotzdem der Eid gegen geheime Gesellschaften bis zum Ende des Ersten Weltkriegs in Kraft blieb, lag daran, dass sich die Vorstellung einer Unterwanderung der bayerischen Schaltstellen durch die Illuminaten langfristig in das bayerische Gedächtnis eingeprägt hatte. Es herrschte eine ständige Angst gegenüber möglichen Umtrieben geheimer Gesellschaften und die Überzeugung, dass insbesondere die Gruppe der staatlichen, geistlichen und militärischen Funktionsträger von allen politisch unzuverlässigen, >subversiv oder revolutionär gesinnten Personen freizuhalten sei. Durch das Wirken des Illuminatenordens wurde die Vorstellung zur scheinbaren Gewissheit, dass alle Gefahren für den Staat auf eine kleine und leicht identifizierbare Gruppe eingegrenzt werden könnten und diese durch rigorose Wachsamkeit, Verfolgung und Bestrafung unschädlich gemacht werden müsse ${ }^{139}$. Insbesondere nach der Französischen Revolution zeigt sich in Bayern eine gedankliche Kausalkette zwischen geheimen Gesellschaften, Französischer Revolution, freiheitlichen Ideen und der Gefährdung bzw. dem revolutionären Umsturz der bestehenden Gesellschafts- und Herrschaftsordnung. Gleichzeitig waren die militärischen Dienstvorschriften in Bayern zur Zeit des Deutschen Bundes von den Ideen der Aufklärung geprägt und die Standespflichten für Offiziere lange Zeit nicht so starr geregelt wie in Preußen. Möglicherweise war auch dies ein Grund, dass hier eine Zusatzregelung geboten schien.

137 HSTA-KA MKr 11530 Geheime Gesellschaften 1814-1920, Eintrag vom 16.11.1918.

$138<$ http://www.historisches-lexikon-bayerns.de/artikel/artikel_44319> (5. August 2015).

139 Vgl. hierzu auch die Überlegungen von Wilson in Bezug auf die Weimarer Verhältnisse: Wilson, Geheimräte gegen Geheimbünde (wie Anm. 30), S. 48. 
Als im Kaiserreich mit der Pranckhschen Heeresreform nach preußischem Vorbild die Reglementierung und geistige Homogenisierung des bayerischen Offizierskorps deutlich zunahmen, die politische Haltung und der außerdienstliche Verkehr der militärischen Führer streng überwacht wurden, hörte die Furcht vor einer Unterwanderung der bayerischen Armee auf. Dass der Eid gegen geheime Gesellschaften weiterhin von den Offizieren geschworen werden musste, lag nun vorrangig an der starken Bedeutung der katholischen Kirche in der bayerischen Öffentlichkeit. Die Mitgliedschaft in geheimen Gesellschaften und insbesondere die Freimaurerei galt dieser als unvereinbar mit dem katholischen Bekenntnis. Die Akten machen sehr deutlich, dass die päpstliche Argumentation im Kriegsministerium nicht mitgetragen wurde und hier starke Sympathien für den Umgang der preußischen Armee mit den Freimaurern bestanden. Dennoch sollte alles vermieden werden, was dem inneren Frieden in Bayern schaden konnte, so dass auf eine Neuregelung verzichtet wurde.

Der rechtliche Umgang in Bayern mit dem Verbot der Mitgliedschaft von Offizieren in geheimen Gesellschaften weist ein Spezifikum auf. Trotz der verschiedenen harten normativen Regelungen gegen Geheimbünde wurde in der Praxis auch bei Verdacht auf Geheimbündelei im Offizierskorps nur sehr behutsam durchgegriffen. Militärische Führer, die wegen der Mitgliedschaft in geheimen Gesellschaften oder in einer der Verschwörung verdächtigten Gruppe überführt wurden, mussten im Regelfall keine oder nur sehr milde Sanktionen befürchten. Sie erfuhren auch keine langfristigen dienstlichen Nachteile, sondern machten nachfolgend oftmals noch groß Karriere.

Die Gründe dafür, dass die bayerischen Herrscher auf strenge Strafen verzichteten, sind vielschichtig. Zuvorderst ist anzuführen, dass die Praxis der Landesherrn, Milde gegenüber den Offizieren walten zu lassen, das monarchische Prinzip stützte, da sie so reuige Offiziere noch fester an sich binden konnten. Hinzu kam, dass die bayerischen Herrscher bis zu einem gewissen Grad auf die Zustimmung ihrer Armee angewiesen waren. Als sich während der Lola-Montez-Krise 1848 die militärischen Führer gegenseitig schützten, beugte sich Ludwig I. und ließ sich von seinen harten Strafandrohungen abbringen. Und schließlich war im Interesse der bayerischen Landesherren, dass Nachrichten über illoyale Offiziere möglichst nicht nach außen drangen. So konnte das öffentliche Ansehen der Armee in Bayern als eine verlässliche Stütze des Throns gewahrt bleiben. 